Research Article

\title{
Experimental Study on Strain Penetration Effects in Fixed-End Rotation of RC Beam-Column Connections with High-Strength Reinforcement
}

\author{
Ling Li $\mathbb{D})^{1}$ Wenzhong Zheng $\left.\mathbb{D}\right)^{1,2,3}$ Ying Wang $\mathbb{D}^{1,2,3}$ and Junke Ma $\mathbb{D}^{1}$ \\ ${ }^{1}$ School of Civil Engineering, Harbin Institute of Technology, Harbin 150090, China \\ ${ }^{2}$ Key Lab of Structures Dynamic Behaviour and Control of the Ministry of Education, Harbin Institute of Technology, \\ Harbin 150090, China \\ ${ }^{3}$ Key Lab Smart Prevention and Mitigation of Civil Engineering Disasters of the Ministry of Industry and Information Technology, \\ Harbin Institute of Technology, Harbin 150090, China \\ Correspondence should be addressed to Wenzhong Zheng; zhengwenzhonghit@163.com
}

Received 23 May 2018; Revised 13 October 2018; Accepted 19 November 2018; Published 13 December 2018

Academic Editor: Giovanni Berselli

Copyright (C) 2018 Ling Li et al. This is an open access article distributed under the Creative Commons Attribution License, which permits unrestricted use, distribution, and reproduction in any medium, provided the original work is properly cited.

\begin{abstract}
The additional fixed-end rotation resulting from the strain penetration of longitudinal reinforcement in a reinforced concrete beam-column connection is a crucial factor for the plastic hinge rotation capacity. When it comes to high-strength reinforcement, the effects of strain penetration on fixed-end rotation become more obvious because of the increase in yield strength. In this study, 42 beam-column connections with high-strength hot rolled ribbed bars were designed and tested under monotonic loading at the beam end. The test results show that the rebar strains gradually decrease from the critical section towards the beam-column connection, thereby proving the existence of strain penetration in the beam-column connection. The slippage of the embedment reinforcement at the beam-column interface and additional fixed-end rotations were obtained from the test results. In addition, a parametric study involving the yield strength and diameter of reinforcement, concrete tensile strength, and embedment length in the beam-column connection was performed to investigate the effects of various parameters on the additional fixed-end rotation. Finally, a new simple and practical calculation model for predicting the additional fixed-end rotation was proposed. The prediction shows good agreement with the experimental results.
\end{abstract}

\section{Introduction}

For reinforced concrete frame structures, the performance of a plastic hinge designed to form at the beam end of the beam-column connection is critical for moment redistribution, deformation capacities, and seismic behaviour of the structures [1]. As the moment is maximum at the critical section of the beam end, a concrete crack will develop and the tensile force at this section is sustained only by the steel reinforcement. Recent research studies have shown that owing to the bond between concrete and reinforcement, the rebar strain penetration extends bilaterally from the critical section toward both shear span and beam-column connection, which all contribute to the rotation of the plastic hinge [2]. This paper focuses on the latter terms of strain penetration. A slippage of the reinforcement at the beamcolumn interface is observed because of the accumulation of the rebar strain along the embedment length in the beamcolumn connection. This slippage is different from the one due to the bond failure and will result in an additional fixedend rotation, which in turn affects the rotation of the plastic hinge region.

Numerous analytical methods on slippage due to strain penetration have been proposed. Some researchers determined the reinforcement strain over the embedment length with a varying local bond-slip relationship [3-9]. This required using iteration loop algorithms to achieve equilibrium of the steel bar. Although this method exhibits good accuracy, the process of this method is complicated. To facilitate the computation, simpler models have been 
proposed [10-13], such as the stepped local bond-slip relationship derived from the experimental results obtained by Alsiwat and Saatcioglu [10]. Using this type of local bondslip relationship, an analytical model of slippage was established by Sezen and Setzler [12] for the cases wherein the embedded length is lower than the development length. Moreover, Tastani and Pasntazopoulou [13] proposed an expression to determined the bar slippage with the rebar strain as variable. For determining the additional fixed-end rotation, several other analytical models have been proposed by using the finite element method. For simplicity, nonlinear rotational springs have been used at the beam-column connection to simulate the end rotation [14-17]. The properties of the springs are obtained using an empirical method; however, this reduces the accuracy of the model. Zhao and Sritharan [18] used a zero-length section element to simulate the fixed-rotation at the beam-column interface by performing a fibre-based analysis. In addition, Paulay and Priestley [19] incorporated the effect of strain penetration on the fixed-end rotation into the equivalent plastic length $L_{\mathrm{sp}}$ using the relationship $L_{\mathrm{sp}}=0.022 f_{\mathrm{y}} d_{\mathrm{b}}$, in which the yield strength $f_{\mathrm{y}}$ and diameter of the steel bar $d_{\mathrm{b}}$ were taken into consideration. Despite the convenience of application, many other factors that affect the properties of slippage were not considered in this method. Tastani and Pasntazopoulou [13] established an analytical expression where the strain penetration length is directly related to the residual bond strength, the diameter, and the hardening modulus of steel bars.

Most of the aforementioned studies were based on theoretical analyses. In this paper, an experimental study on the additional fixed-end rotation of reinforced concrete beam-column connections due to strain penetration is presented. 18 interior beam-column connections with straight high-strength reinforcement and 24 exterior beamcolumn connections with hooked and headed high-strength reinforcement were tested under monotonic loading. The parameters that potentially affect the slippage of the embedment reinforcement in the beam-column connection, including the yield strength and diameter of the highstrength reinforcement, concrete tensile strength, and embedment length in the beam-column connection were investigated to obtain the development trends of the additional fixed-end rotation with respect to each parameter. The main objective of this study was to propose a simple calculation model of the addition fixed-end rotation due to strain penetration at the yielding (rebar strain at the critical section reaches the yield strain) and nominal ultimate states (concrete strain in the extreme compressed fibre reaches the ultimate strain). In this model, the parameters generally used in the structural design are considered instead of the ones used in the theoretical derivation to make the proposed model more practical.

\section{Experimental Program}

2.1. Specimen Details. A total of 30 specimens were designed and tested in this study. Each specimen comprises two cantilever beams, a middle column, and a bottom beam. The specimens were divided into two types, as listed in Table 1. 18 specimens were used to model the interior beamcolumn connections, labelled using the letter I as the first letter. 12 specimens were used to model the exterior beam-column connections, each of which were investigated as two exterior beam-column connections and labelled using the letter $\mathrm{E}$ as the first letter. The cantilever beams of all the specimens have the same rectangular cross section of $200 \mathrm{~mm} \times 350 \mathrm{~mm}$ with an overall length of $1000 \mathrm{~mm}$. For the I-type specimens, the cross-sectional width of each middle column was $300 \mathrm{~mm}$; however, different cross-sectional depths, i.e., $400 \mathrm{~mm}, 600 \mathrm{~mm}$, and $800 \mathrm{~mm}$, were set to study the strain penetration of the tensile reinforcement with different embedment lengths throughout the beam-column connections. The height of each column was $1100 \mathrm{~mm}$. For the E-type specimens, the height and cross-sectional dimension of the middle columns were $1350 \mathrm{~mm}$ and $300 \mathrm{~mm} \times 450 \mathrm{~mm}$, respectively. Four control variables were considered in the design, namely, the yield strength of the tensile reinforcement, the diameter of the tensile reinforcement in the beam-column connection, straight embedment length of the tensile reinforcement in the beam-column connection, and the concrete grade. These variables were all reflected in the "specimens No." The grades of the tensile reinforcement were HRB500 and HRB600 (specified in the Chinese code for design of concrete structures GB 50010-2010 [20]), represented by the second letter in the "specimens No.," corresponding to the letters $\mathrm{A}$ and $\mathrm{B}$, respectively. The subsequent number indicates the straight embedment length of the tensile reinforcement in the beam-column connection. The levels of the concrete grade were C40, C50, and C60 as per the Chinese code [20], corresponding to the third term in the "specimen No." The last term represents the diameter of the tensile reinforcement. For example, "IA-400-C40-18" represents an interior beam-column connection with a tensile reinforcement grade of HRB500 and a concrete grade of C40. The straight embedment length and the diameter of the tensile reinforcement in the beam-column connection are $400 \mathrm{~mm}$ and $18 \mathrm{~mm}$, respectively.

To ensure that the test beams exhibit good ductile performance and to prevent brittle failure, appropriate tensile reinforcement ratios varying from $0.9 \%-1.5 \%$ were selected for the cantilever beams. Meanwhile, sufficient stirrups were arranged in all the beams to avoid shear failure, and the strong column-weak beam requirement was followed in the design. Table 1 and Figure 1 present the details of reinforcement arrangement and specimen dimensions, respectively.

2.2. Materials Properties. The material tests included the tensile test for reinforcement and compressive cube test for concrete. The reinforcements are tested under uniaxial tension. The gauge length of the reinforcement is $500 \mathrm{~mm}$, and the reinforcement stress is evaluated based on the nominal diameter of the bars. The stress-strain relationships of the tensile reinforcement are shown in 
TABLE 1: Reinforcement of the test specimens.

\begin{tabular}{|c|c|c|c|c|c|c|c|c|c|}
\hline \multirow[b]{2}{*}{ No. } & \multicolumn{7}{|c|}{ Beam } & \multicolumn{2}{|c|}{ Column } \\
\hline & Beam no. & $\begin{array}{l}\text { Top } \\
\text { (1) }\end{array}$ & $\begin{array}{l}\text { Tensile } \\
\text { reinforcement } \\
\text { ratios (\%) }\end{array}$ & $\begin{array}{l}\text { Stirrup } \\
\text { (3) }\end{array}$ & $\begin{array}{c}\text { Stirrup } \\
\text { ratios (\%) }\end{array}$ & $\begin{array}{c}\text { Anchorage } \\
\text { type }\end{array}$ & $\begin{array}{l}l_{\mathrm{a}} / l_{\mathrm{ah}} \\
(\mathrm{mm})\end{array}$ & $\begin{array}{l}\text { Longitudinal } \\
\text { reinforcement } \\
\text { (4) }\end{array}$ & $\begin{array}{l}\text { Stirrup } \\
\text { (5) }\end{array}$ \\
\hline 1 & IA-400-C40-18 & $3 \Phi 18$ & 1.17 & \$10@100 & 0.79 & - & 400 & $8 \$ 18$ & \$10@100 \\
\hline 2 & IA-600-C40-20 & $2 \Phi 20$ & 0.97 & \$10@100 & 0.79 & - & 600 & $8 \$ 18$ & \$10@100 \\
\hline 3 & IA-800-C40-22 & $2 \Phi 22$ & 1.17 & \$10@80 & 0.98 & - & 800 & $10 \Phi 18$ & \$10@100 \\
\hline 4 & IA-400-C50-18 & $3 \Phi 18$ & 1.17 & \$10@100 & 0.79 & - & 400 & $8 \$ 18$ & \$10@100 \\
\hline 5 & IA-600-C50-20 & $3 \Phi 20$ & 1.45 & \$10@100 & 0.79 & - & 600 & $8 \$ 18$ & \$10@100 \\
\hline 6 & IA-800-C50-22 & $2 \Phi 22$ & 1.17 & \$10@80 & 0.98 & - & 800 & $10 \$ 18$ & \$10@100 \\
\hline 7 & IA-400-C60-18 & $3 \Phi 18$ & 1.17 & \$10@100 & 0.79 & - & 400 & $8 \Phi 18$ & \$10@100 \\
\hline 8 & IA-600-C60-20 & $3 \Phi 20$ & 1.45 & ф10@100 & 0.79 & - & 600 & $8 \$ 18$ & \$10@100 \\
\hline 9 & IA-800-C60-22 & $3 \Phi 22$ & 1.17 & \$10@80 & 0.98 & - & 800 & $10 \$ 18$ & \$10@100 \\
\hline 10 & IB- $400-C 40-18$ & 3 \$一ा 18 & 1.17 & \$10@100 & 0.79 & - & 400 & $8 \$ 18$ & \$10@100 \\
\hline 11 & IB-600-C40-20 & 2 卌20 & 0.97 & \$10@100 & 0.79 & - & 600 & $8 \Phi 18$ & \$10@100 \\
\hline 12 & IB-800-C40-22 & $2 \mathbb{\$} 22$ & 1.17 & \$10@80 & 0.98 & - & 800 & $10 \$ 18$ & \$10@100 \\
\hline 13 & IB-400-C50-18 & 3 卌 18 & 1.17 & ф10@100 & 0.79 & - & 400 & $8 \$ 18$ & \$10@100 \\
\hline 14 & IB-600-C50-20 & $2 \mathbb{\$} 20$ & 0.97 & \$10@100 & 0.79 & - & 600 & $8 \$ 18$ & \$10@100 \\
\hline 15 & IB-800-C50-22 & 2 曹22 & 1.17 & ф10@80 & 0.98 & - & 800 & $10 \$ 18$ & \$10@100 \\
\hline 16 & IB-400-C60-18 & 3 曹 18 & 1.17 & \$10@100 & 0.79 & - & 400 & $8 \nsubseteq 18$ & \$10@100 \\
\hline 17 & IB-600-C60-20 & 3 曹20 & 1.45 & \$10@100 & 0.79 & - & 600 & $8 \nsubseteq 18$ & \$10@100 \\
\hline 18 & IB-800-C60-22 & $2 \$ 22$ & 1.17 & \$10@80 & 0.98 & - & 800 & $10 \$ 18$ & \$10@100 \\
\hline \multirow{2}{*}{19} & EA-430-C40-18 & $3 \Phi 18$ & 1.17 & \$10@100 & 0.79 & Straight & 430 & $8 \Phi 18$ & \multirow{2}{*}{ \$10@100 } \\
\hline & EA-210-C40-22 & $2 \Phi 22$ & 1.17 & ф10@100 & 0.79 & Hooked & 210 & $8 \Phi 18$ & \\
\hline \multirow{2}{*}{20} & EA-330-C40-20 & $2 \Phi 20$ & 0.97 & ф10@150 & 0.52 & Hooked & 330 & $8 \$ 18$ & \multirow{2}{*}{ \$10@100 } \\
\hline & EA-190-C40-20 & $2 \Phi 20$ & 0.97 & \$10@150 & 0.52 & Headed & 190 & $8 \Phi 18$ & \\
\hline \multirow{2}{*}{21} & EA-380-C50-18 & $3 \Phi 18$ & 1.17 & ф10@150 & 0.52 & Straight & 380 & $8 \$ 18$ & \multirow{2}{*}{ \$10@100 } \\
\hline & EA-190-C50-22 & $2 \Phi 22$ & 1.17 & ф10@150 & 0.52 & Hooked & 190 & $8 \$ 18$ & \\
\hline \multirow{2}{*}{22} & EA-300-C50-20 & $3 \Phi 20$ & 1.45 & ф10@100 & 0.79 & Hooked & 300 & $8 \$ 18$ & \multirow{2}{*}{ \$10@80 } \\
\hline & EA-420-C50-20 & $3 \Phi 20$ & 1.45 & \$10@100 & 0.79 & Straight & 420 & $8 \$ 18$ & \\
\hline \multirow{2}{*}{23} & EA-350-C60-18 & $3 \Phi 18$ & 1.17 & ф10@150 & 0.52 & Straight & 350 & $8 \$ 18$ & \multirow{2}{*}{ \$10@100 } \\
\hline & EA-300-C60-22 & $2 \Phi 22$ & 1.17 & ф10@150 & 0.52 & Hooked & 300 & $8 \$ 18$ & \\
\hline \multirow{2}{*}{24} & EA-270-C60-20 & $3 \Phi 20$ & 1.45 & ф10@100 & 0.79 & Headed & 270 & $8 \Phi 18$ & \multirow{2}{*}{ \$10@80 } \\
\hline & EA-160-C60-20 & $3 \Phi 20$ & 1.45 & \$10@100 & 0.79 & Hooked & 160 & $8 \$ 18$ & \\
\hline \multirow{2}{*}{25} & EB-420-C40-18 & 3 \$\$ 18 & 1.17 & ф10@100 & 0.79 & Straight & 420 & $8 \nsubseteq 18$ & \multirow{2}{*}{ \$10@100 } \\
\hline & EB-230-C40-22 & $2 \mathbb{\$ 1} 22$ & 1.17 & ф10@100 & 0.79 & Hooked & 230 & $8 \$ 18$ & \\
\hline \multirow{2}{*}{26} & EB-380-C40-20 & $2 \mathbb{\$} 20$ & 0.97 & \$10@150 & 0.52 & Hooked & 380 & $8 \$ 18$ & \multirow{2}{*}{ \$10@100 } \\
\hline & EB-220-C40-20 & $2 \mathbb{\$} 20$ & 0.97 & ф10@150 & 0.52 & Headed & 220 & $8 \$ 18$ & \\
\hline \multirow{2}{*}{27} & EB-420-C50-18 & 3 曹18 & 1.17 & \$10@100 & 0.79 & Straight & 420 & $8 \$ 18$ & \multirow{2}{*}{ \$10@100 } \\
\hline & EB-210-C50-22 & $2 \Phi 22$ & 1.17 & \$10@100 & 0.79 & Hooked & 210 & $8 \$ 18$ & \\
\hline \multirow{2}{*}{28} & EB-340-C50-20 & $2 \mathbb{\$} 20$ & 0.97 & \$10@150 & 0.52 & Hooked & 340 & $8 \$ 18$ & \\
\hline & EB-420-C50-20 & $2 \mathbb{2} 20$ & 0.97 & \$10@150 & 0.52 & Straight & 420 & $8 \$ 18$ & \$10@100 \\
\hline & EB-400-C60-18 & 3 \#झ 18 & 1.17 & \$10@100 & 0.79 & Straight & 400 & $8 \$ 18$ & \\
\hline 29 & EB-340-C60-22 & 2 曹22 & 1.17 & ф10@150 & 0.52 & Hooked & 340 & $8 \$ 18$ & \$10@100 \\
\hline & EB-310-C60-20 & 3 正20 & 1.45 & ф10@80 & 0.98 & Headed & 310 & $8 \Phi 18$ & \\
\hline 30 & EB-180-C60-20 & 3 业20 & 1.45 & ф10@80 & 0.98 & Hooked & 180 & $8 \$ 18$ & \$10@80 \\
\hline
\end{tabular}

This table should be read in conjunction with Figure 1. The bottom longitudinal reinforcements in all the cantilever beams were denoted by (2), as shown in the cross section A-A in Figure 1. Two HRB400 steel bars with a diameter of $10 \mathrm{~mm}$ were used as (2) steel bars. The top and bottom longitudinal reinforcements in all the bottom beams of the specimens were denoted by (6), as shown in the cross section C-C in Figure 1. Three HRB400 steel bars with a diameter of 18 mm were used as (6) steel bars. The transverse reinforcement in all the bottom beams of the specimens were denoted by (7), as shown in the cross section C-C in Figure 1. HPB300 steel bars with a diameter of $10 \mathrm{~mm}$ were used as 7 steel bars with a spacing of $100 \mathrm{~mm} . \Phi, \Phi$, $\Phi$, and $\Phi$, respectively, indicate reinforcement grades of HPB300, HRB400, HRB500, and HRB600. $2 \$ 10$ bars (2) were used as the bottom longitudinal reinforcements in all the cantilever beams. In the bottom beams of the specimens, $3 \$ 18$ bars (6) were used as the top and bottom longitudinal reinforcements and $\$ 10$ bars with a spacing of $100 \mathrm{~mm}(7)$ were used as the transverse reinforcement.

Figure 2, and the values of the measured parameters are listed in Table 2. The cubic strength of the concrete $f_{\text {cu }}$ was calculated using cubes with a side of $150 \mathrm{~mm}$, tested along with the test specimens. The cubes were prepared and cured in the same manner as the test specimens. Table 3 lists the properties of the concrete.
2.3. Test Setup and Procedure. Figure 3 shows the test rigs and instrumentations. The bottom beam was connected to the ground with two symmetrical bolts on both sides of the middle column. A point monotonic load was applied symmetrically using two loading jacks at the end of the cantilever beams. A sensor was placed on each loading jack 

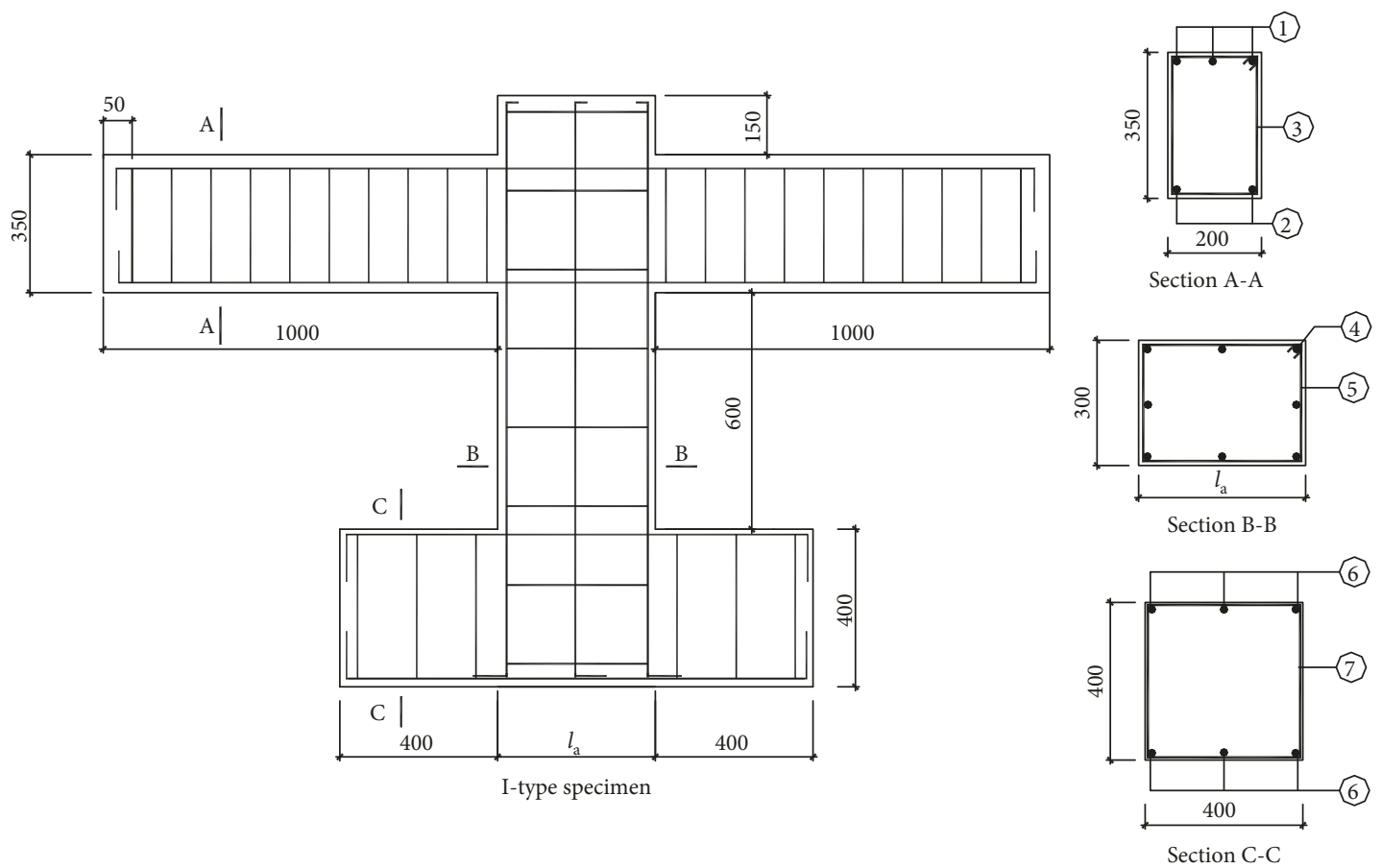

(a)
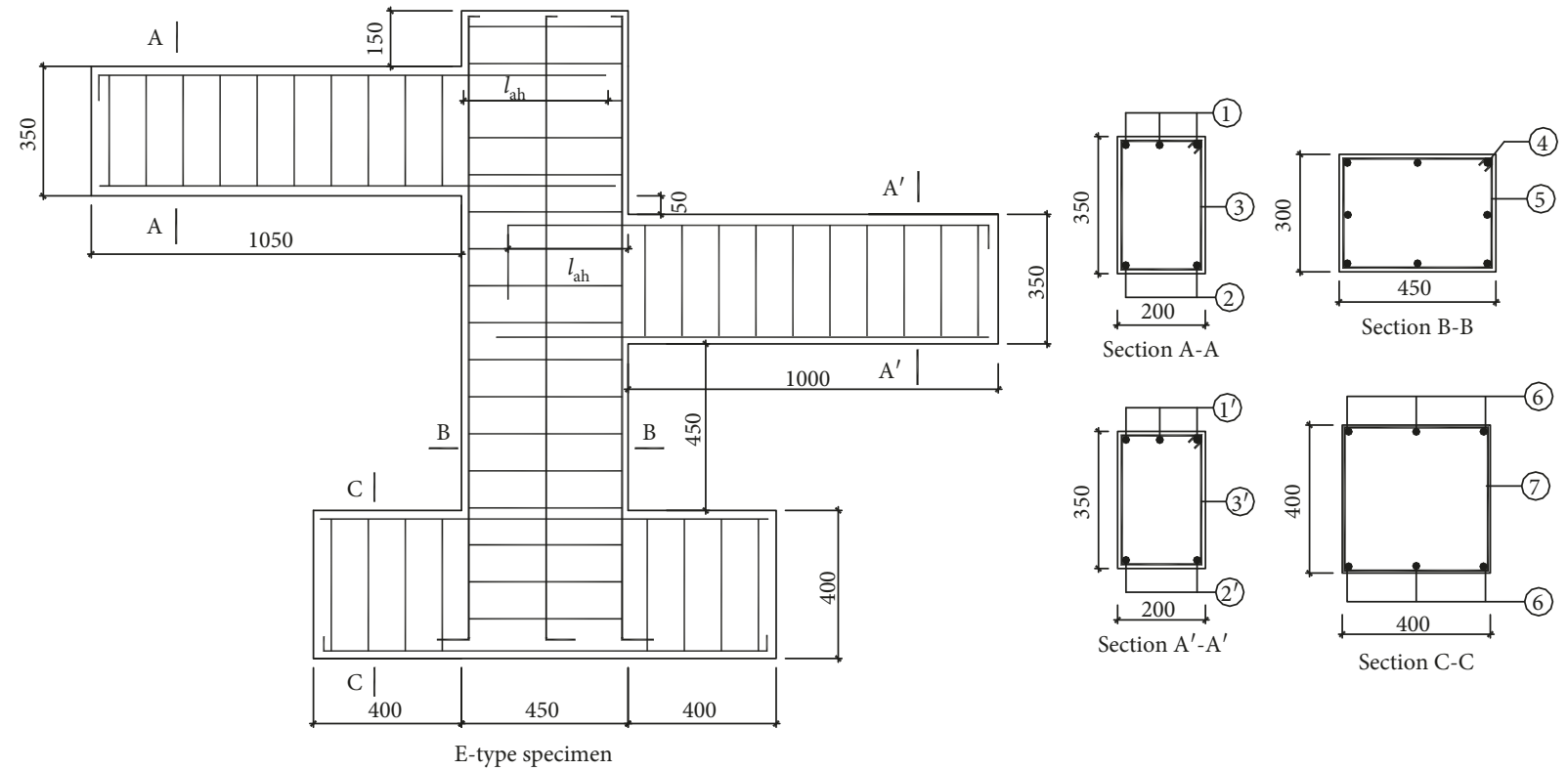

(b)

FIGURE 1: Details of the reinforcement arrangement and specimen size. (a) Interior beam-column connection. (b) Exterior beam-column connection.

to measure the value of the applied loads and to ensure that the two loads are equal at all times. Two displacement transducers were located underneath the loading point to measure the deflection of the beams. In particular, for the E-type specimens, the heights of the two cantilever beams on both sides of the column were different, as shown in Figure 1(b). In order to prevent the cracks on the sides of the column from affecting strain penetration, an eccentric axial force was applied at the top of the column to balance the flexure moment of the column, as shown in Figure 3(b). Strain gauges with a width of $1 \mathrm{~mm}$ and length of $2 \mathrm{~mm}$ were attached at the intervals of $40 \mathrm{~mm}$ to investigate the strain penetration of the longitudinal tensile reinforcement in the beam-column connections. Figure 4 shows the locations of the strain gauges. To accurately obtain the strain, the strain gauges were placed along the notch of the reinforcement, which was slotted adjacent to the longitudinal ribs, as shown in Figure 5. In this way, the loss of the effective area of the 


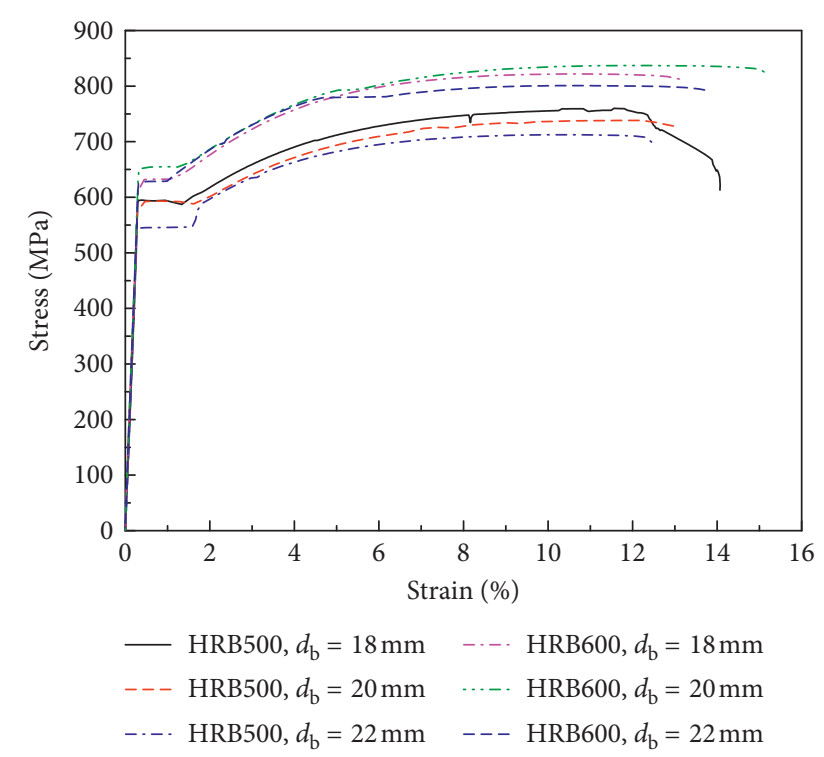

FIgURE 2: Stress-strain relationships of the tensile reinforcement.

TABLE 2: Material properties of reinforcement.

\begin{tabular}{lccccc}
\hline Grade & $\begin{array}{c}\text { Diameter } \\
(\mathrm{mm})\end{array}$ & $\begin{array}{c}\text { Yield } \\
\text { strength } \\
f_{\mathrm{y}}(\mathrm{MPa})\end{array}$ & $\begin{array}{c}\text { Ultimate } \\
\text { strength } \\
f_{\mathrm{u}}(\mathrm{MPa})\end{array}$ & $\begin{array}{c}\text { Yield } \\
\text { strain } \\
\varepsilon_{\mathrm{y}}\end{array}$ & $\begin{array}{c}\text { Percentage } \\
\text { elongation } \\
\text { at maximum } \\
\text { force } \varepsilon_{\mathrm{u}}\end{array}$ \\
\hline HPB300 & 10 & 381 & 513 & 0.00191 & 0.150 \\
\hline \multirow{2}{*}{ HRB400 } & 10 & 498 & 632 & 0.00249 & 0.148 \\
& 18 & 460 & 621 & 0.00230 & 0.136 \\
\hline \multirow{3}{*}{ HRB500 } & 18 & 590 & 760 & 0.00295 & 0.116 \\
& 20 & 581 & 732 & 0.00291 & 0.122 \\
HRB600 & 22 & 543 & 713 & 0.00272 & 0.113 \\
& 18 & 631 & 825 & 0.00316 & 0.108 \\
& 22 & 654 & 837 & 0.00327 & 0.104 \\
\hline
\end{tabular}

TABLe 3: Materials properties of concrete.

\begin{tabular}{llll}
\hline Grade & C40 & C50 & C60 \\
\hline Cubic strength, $f_{\text {cu }}(\mathrm{MPa})$ & 50.6 & 59.2 & 74.3 \\
Compressive strength, $f_{\mathrm{c}}^{\prime}(\mathrm{MPa})$ & 40.5 & 47.4 & 61.9 \\
Tensile strength, $f_{\mathrm{ct}}(\mathrm{MPa})$ & 3.41 & 3.73 & 4.22 \\
\hline
\end{tabular}

For concrete below C50 grade, the compressive strength $f_{\mathrm{c}}{ }^{\prime}$ was calculated as 0.8 times the cubic strength $f_{\text {cu }}$; the compressive strength $f_{\mathrm{c}}^{\prime}$ of C60 concrete was calculated as 0.833 times the cubic strength $f_{\text {cu }}$; the tensile strength $f_{\text {ct }}$ was calculated by $f_{\mathrm{ct}}=0.395 f_{\mathrm{cu}}^{0.55}[20]$.

bars and the influence on the bonding performance of the tensile longitudinal reinforcement were minimised to a significant extent.

\section{Experimental Results}

3.1. Global Behaviour of Test Specimens. Figure 6 shows the variation in the load with respect to the vertical displacement of the test specimens in the loading process. All the specimens were observed to experience four stages: the appearance of the first major crack (Point A), yielding state
(Point B), nominal ultimate limit state (Point C), and actual ultimate limit state (Point D). Among these, the yielding state is defined as the state when the strain of the tensile reinforcement at the critical section reaches the yield strain. The nominal flexural strength of the critical section is reached when the strain in the extreme compressed fibre reaches the ultimate strain [21], which is defined as the nominal ultimate limit state in this paper. Furthermore, the real ultimate limit state corresponds to the maximum loadcarrying resistance of the specimens.

From the start of the test until Point A, the specimens did not crack and their deformations were linearly elastic. At Point A, first major cracks appeared at the section adjacent to the beam-column connection (Figure $7(\mathrm{~b})$ ). With the increase in the load, more cracks gradually developed in the span (Figure $7(\mathrm{a})$ ) and the beams behaved quite linearly in the deflection curves before Point B. After Point B, the deformation increased relatively quickly with the increase in the load. The number of cracks no longer increased; however, the width of cracks increased. It should be noted that the distances among the cracks are important for strain penetration in the shear span, which has been comprehensively studied by Megaloopikonomou et al. [2]. The region, ranging from the crack section toward the uncrack part of the shear span until the rebar strain coordinates with the deformation of the surrounding concrete cover, was defined as the "disturbed" region. In view of whether the next crack is formed in the "disturbed" region of the previous crack, different methods for evaluating the strain and slip of the reinforcement along the shear span have been proposed in the literature [2]. At Point C, a slight concrete compressive failure was observed at the critical cross section. Subsequently, more horizontal compressive cracks gradually developed at the compressive zone near the critical section (Figure 7(c)). However, the load was largely constant with the rapid increase in the deflection. It can be explained that the confined stirrups of the beams (the range of stirrup volumetric ratios is $1.2 \% \sim 1.9 \%$ ) would improve the ultimate compressive strength and ultimate strain of the confined compression concrete to some extent, thereby improving the ductilities of the test beam. Until the peak Point $\mathrm{D}$, the concrete was obviously crushed (Figure $7(\mathrm{~d})$ ) and the curves entered the descending stage that the load decreased with the increase in the deflection. As shown in Figure 6, the deflections of the east span beam and west span beam for the one specimen were largely symmetrical owing to their equal longitudinal steel ratios. For each comparison group with the same concrete grade and the same ratios of the tensile reinforcement, a very similar behaviour was observed before the yielding state (Point B). After Point B, the beams with a higher grade of reinforcement developed a higher flexural capacity. Tables 4 and 5 list the loads corresponding to the characteristic point of the specimens.

3.2. Rebar Strain Distribution along the Embedment Length. Figures 8 and 9 show the strain distribution (at the yielding and nominal ultimate limit states) of the straight embedment reinforcement in the interior beam-column 


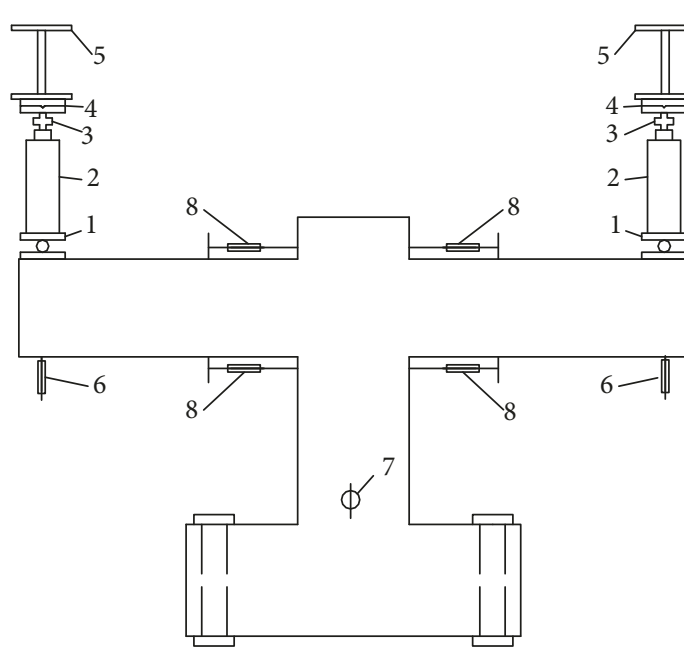

(i) Schematic

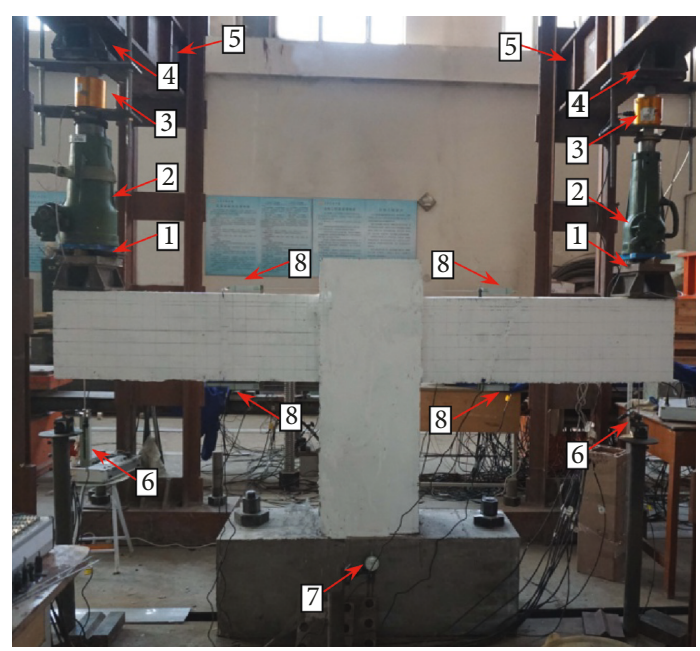

(ii) Photograph

(a)

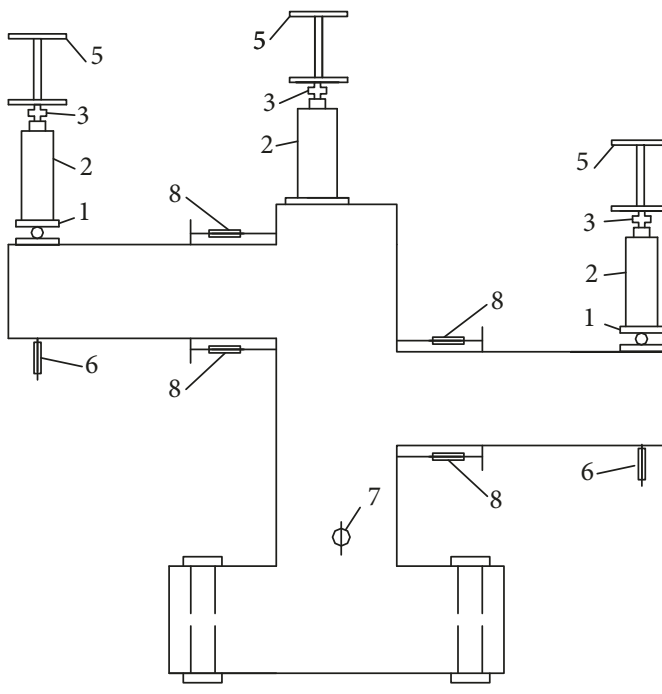

(i) Schematic

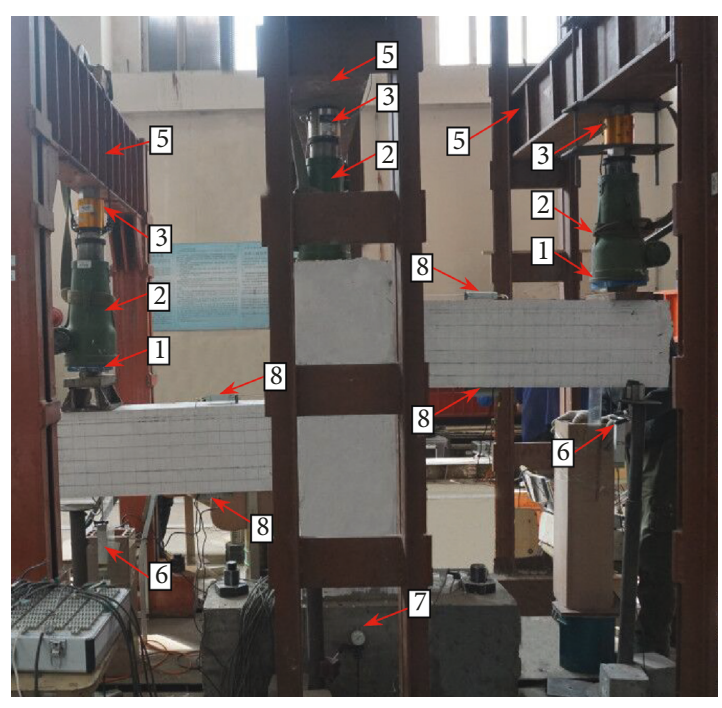

(ii) Photograph

(b)

FIgURE 3: Test rigs and instrumentations. (a) Interior beam-column connection test: (i) schematic; (ii) photograph. (b) Exterior beamcolumn connection test: (i) schematic; (ii) photograph. (1) Rolling hinge support. (2) Loading jack. (3) Loading sensor. (4) Blade hinge support. (5) Trestle. (6) Displacement transducers. (7) Dial indicator. (8) Extensometer.

connection and exterior beam-column connection, respectively. In Figure 8, the origin of the abscissa represents the midpoint of the continuous reinforcement through the interior beam-column connection, and the one in Figure 9 represents the free end near the headed part of the anchorage reinforcement in the exterior connection (consistent with Figure 4). The figures demonstrate the occurrence of strain penetration in the beam-column connection that the rebar strain gradually decreases from the critical section to the coordinate origin and consequently slippage at the beamcolumn interface. Moreover, for the same grade of reinforcement, the rebar strain at the coordinate origin decreases with the increase in the straight embedment length. A longer embedment length results in lower bond stresses near the coordinate origin; however, the accumulation of the bonding stresses along the embedment length increases, denoting a lower strain of reinforcement at the coordinate origin. At the nominal ultimate limit state, the rebar strains are concentrated near the beam-column interface, and they were observed to decrease sharply to the yield strain point and then decrease slowly until the coordinate origin.

\subsection{Additional Fixed-End Rotation due to Strain Penetration.} Figures 10(a) and 10(b) illustrate the additional fixed-end rotation $\theta_{\text {slip }}$ at the beam-column interface due to the strain penetration of the tensile reinforcement inside the interior and exterior beam-column connections. $\theta_{\text {slip }}$ is equal to the slippage of the embedment reinforcement $s$ divided by the depth of the tensile zone $\left(d-x_{\mathrm{c}}\right)$ as follows: 


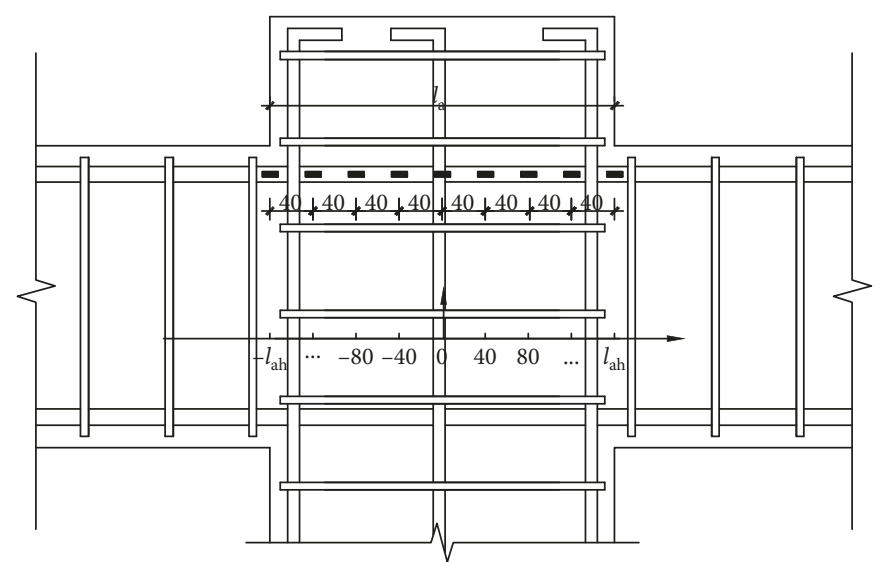

(a)

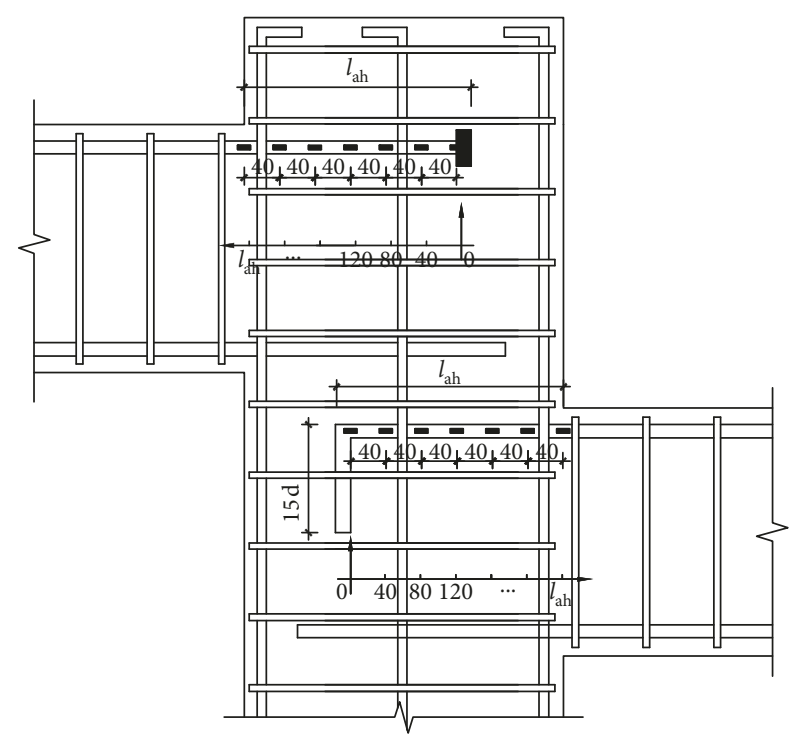

(b)

FIgURE 4: Configuration of strain gauges. (a) Interior beam-column connection. (b) Exterior beam-column connection.

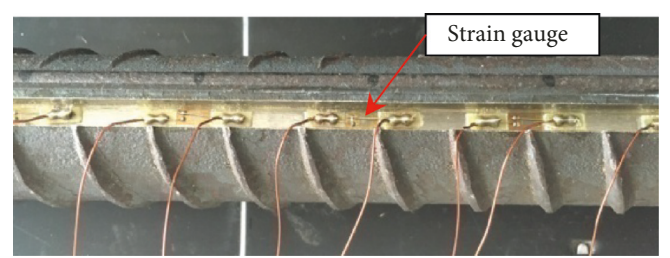

(a)

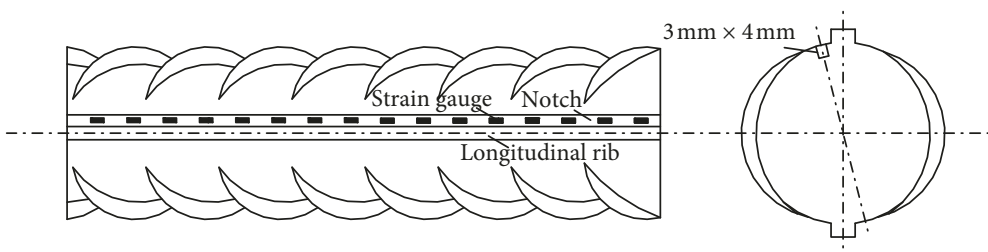

(b)

Figure 5: Strain gauges attached along the notch. (a) Photograph. (b) Schematic.

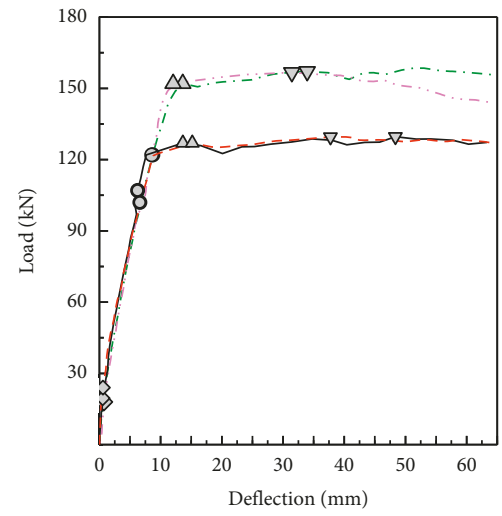

$\diamond$ Point A IA-400-C40-18 (west span)

○ Point B - - - IA-400-C40-18 (east span)

$\triangle$ Point C -. - IB-400-C40-18 (west span)

$\nabla$ Point D …. IB-400-C40-18 (east span)

(a)

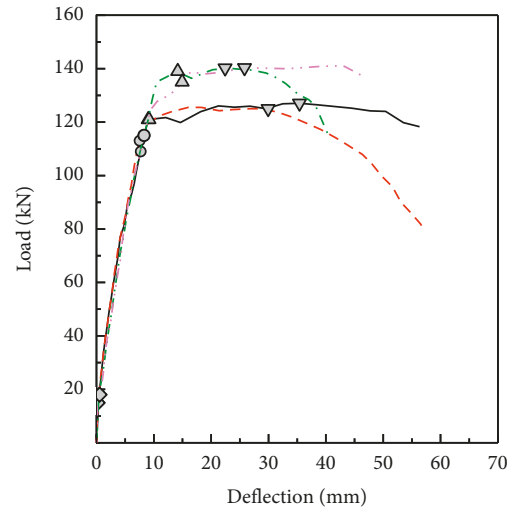

$\diamond$ Point A — IA-600-C40-20 (west span)

○ Point B - - - IA-600-C40-20 (east span)

$\triangle$ Point C _... IB-600-C40-20 (west span)

$\nabla$ Point D … IB-600-C40-20 (east span)

(b)

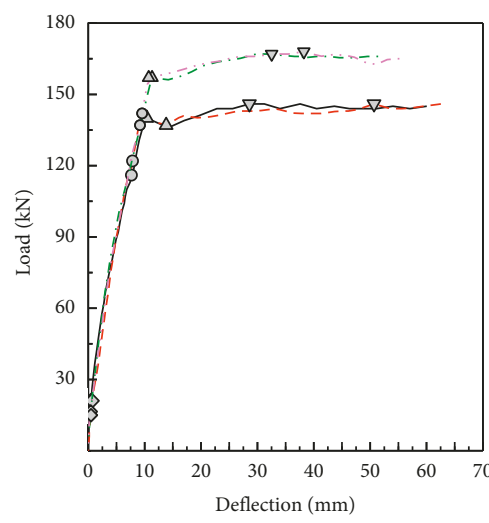

$\diamond$ Point A IA-800-C40-22 (west span)

○ Point B - - - IA-800-C40-22 (east span)

$\triangle$ Point C - . - IB-800-C40-22 (west span)

$\nabla$ Point D …. IB-800-C40-22 (east span)

(c)

Figure 6: Continued. 


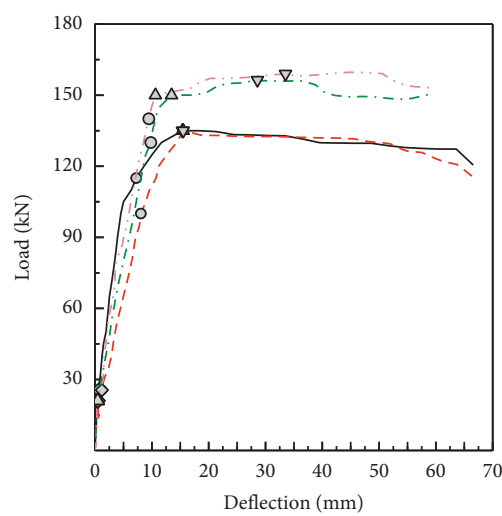

$\triangle$ Point A — IA-400-C50-18 (west span) ○ Point B - - - IA-400-C50-18 (east span)

$\triangle$ Point C -... IB-400-C50-18 (west span)

$\nabla$ Point D …. IB-400-C50-18 (east span)

(d)

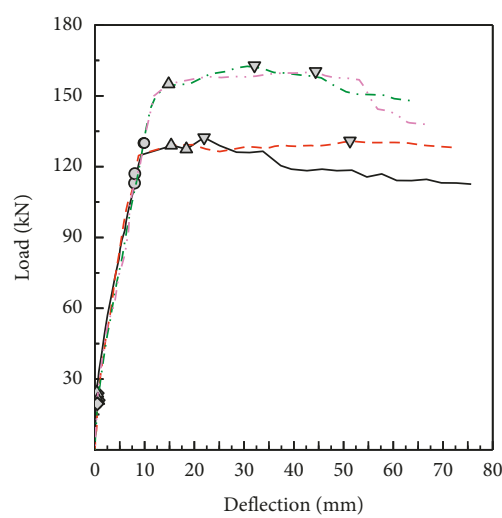

$\diamond$ Point A $\longrightarrow$ IA-400-C60-18 (west span)

o Point B - - - IA-400-C60-18 (east span)

$\triangle$ Point C - - . IB-400-C60-18 (west span)

$\nabla$ Point D .... IB-400-C60-18 (east span)

(g)

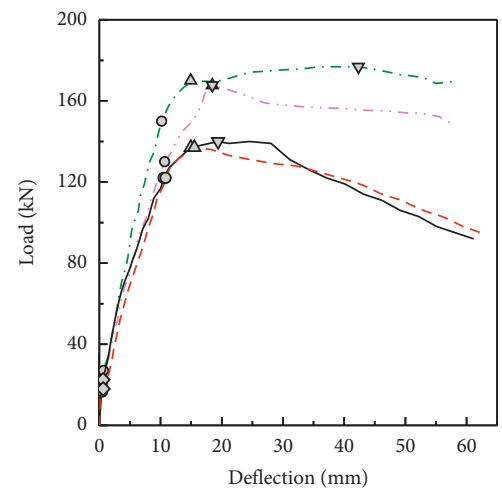

$\diamond$ Point A — EA-420-C40-18 (west span)

- Point B - - EA-230-C40-22 (east span)

$\triangle$ Point C - - EB-420-C40-18 (west span)

$\nabla$ Point D .... EB-230-C40-22 (east span)

(j)
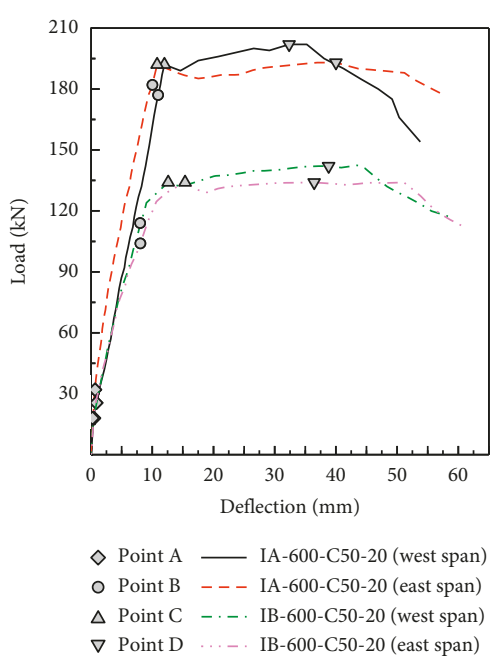

(e)

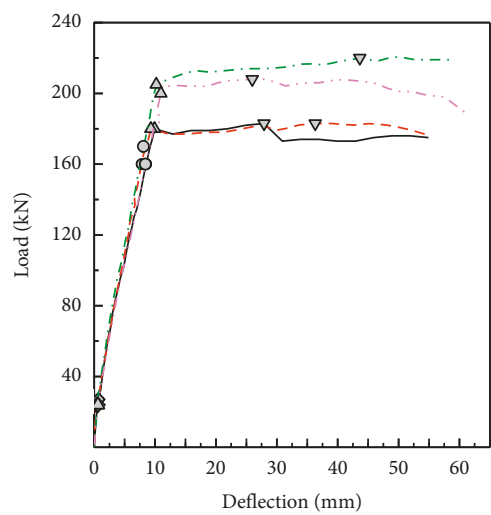

$\diamond$ Point A IA-600-C60-20 (west span)

o Point B - - - IA-600-C60-20 (east span)

$\triangle$ Point C -.. IB-600-C60-20 (west span)

$\nabla$ Point D … . IB-600-C60-20 (east span)

(h)

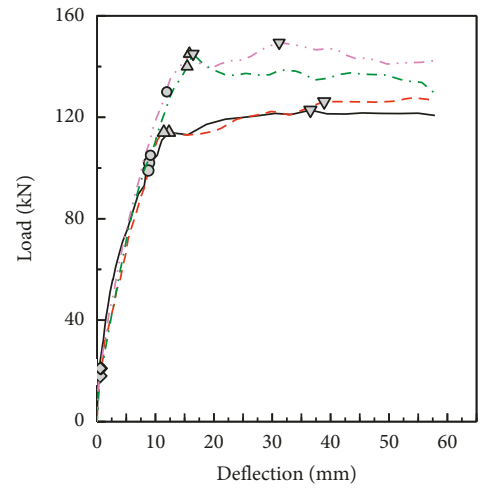

$\diamond$ Point A — EA-330-C40-20 (west span)

o Point B - - - EA-190-C40-20 (east span)

$\triangle$ Point C - . . EB-380-C40-20 (west span)

$\nabla$ Point D .... . EB-220-C40-20 (east span)

(k)

FIgUre 6: Continued.

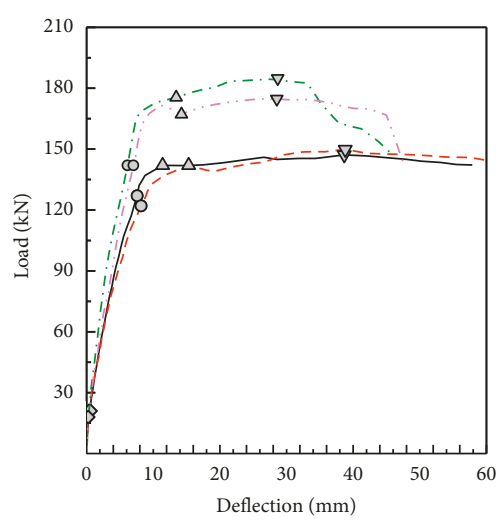

$\triangle$ Point A $\longrightarrow$ IA-800-C50-22 (west span)

○ Point B - - - IA-800-C50-22 (east span)

$\triangle$ Point C -. - IB-800-C50-22 (west span)

$\nabla$ Point D … . IB-800-C50-22 (east span)

(f)

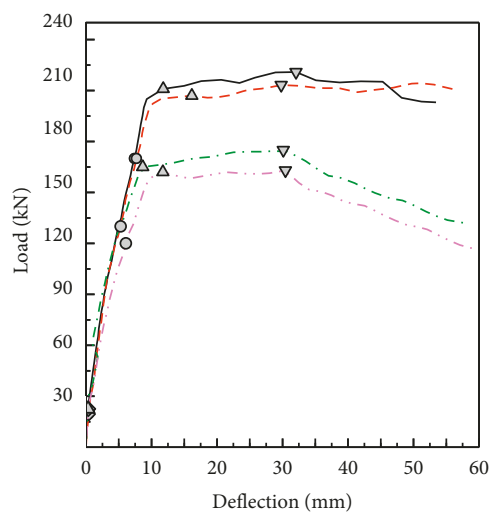

$\diamond$ Point A $\longrightarrow$ IA-800-C60-22 (west span)

- Point B - - - IA-800-C60-22 (east span)

$\triangle$ Point C - . . IB-800-C60-22 (west span)

$\nabla$ Point D .... . IB-800-C60-22 (east span)

(i)

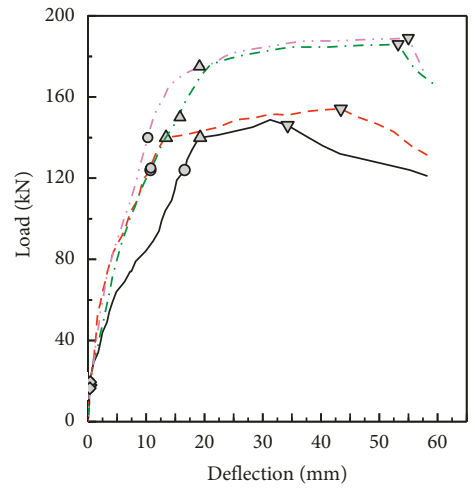

$\diamond$ Point A — EA-380-C50-18 (west span)

- Point B - - - EA-190-C50-22 (east span)

$\triangle$ Point C - . . EB-420-C50-18 (west span)

$\nabla$ Point D ..... EB-210-C50-22 (east span)

(1) 


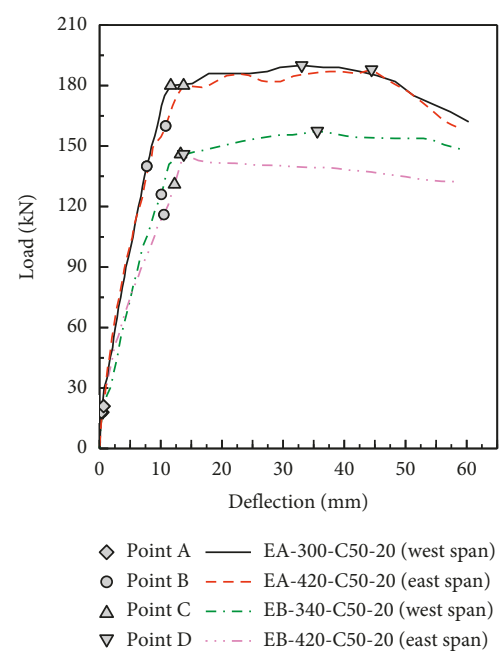

(m)

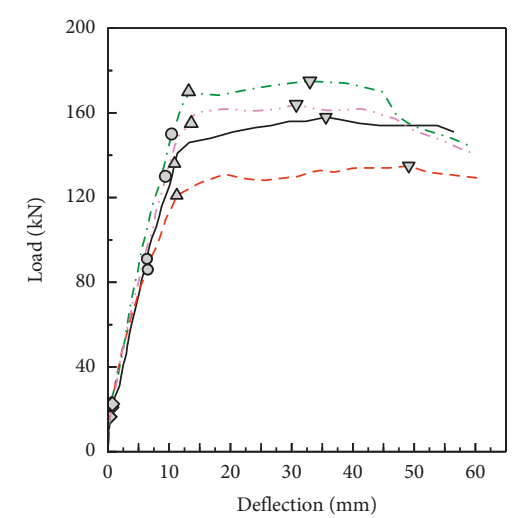

$\diamond$ Point A — EA-350-C60-18 (west span) ○ Point B - - EA-300-C60-22 (east span) $\triangle$ Point C - - . EB-400-C60-18 (west span) $\nabla$ Point D ..... EB-340-C60-22 (east span)

(n)

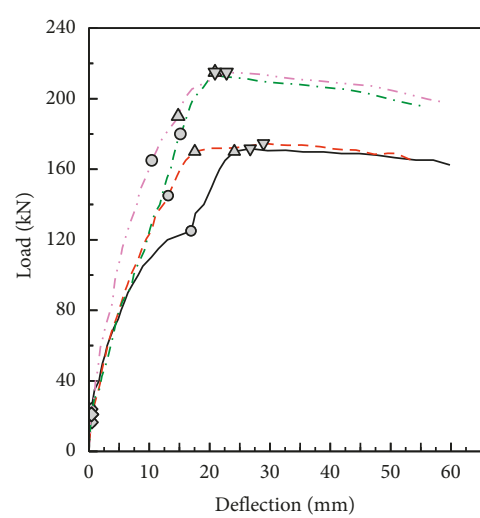

$\diamond$ Point A — EA-270-C60-20 (west span) - Point B - - EA-160-C60-20 (east span) $\triangle$ Point C - - - EB-310-C60-20 (west span) $\nabla$ Point D … . EB-180-C60-20 (east span)

(o)

Figure 6: Load versus displacement curve. (a) IA/B-C40-18. (b) IA/B-C40-20. (c) IA/B-C40-22. (d) IA/B-C50-18. (e) IA/B-C50-20. (f) IA/ B-C50-22. (g) IA/B-C60-18. (h) IA/B-C60-20. (i) IA/B-C60-22. (j) EA/B-C40-18/22. (k) EA/B-C40-20. (l) EA/B-C50-18/22. (m) EA/B-C5020. (n) EA/B-C60-18/22. (o) EA/B-C60-20.
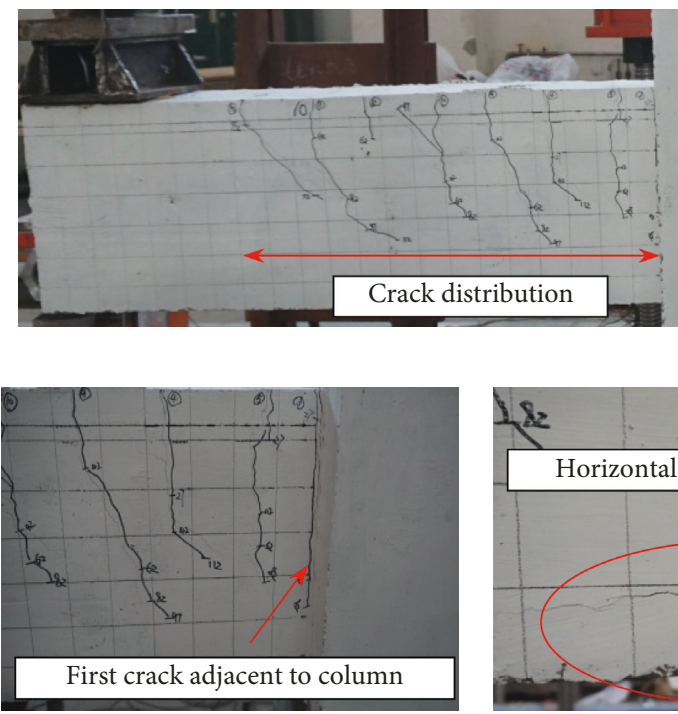

(b)

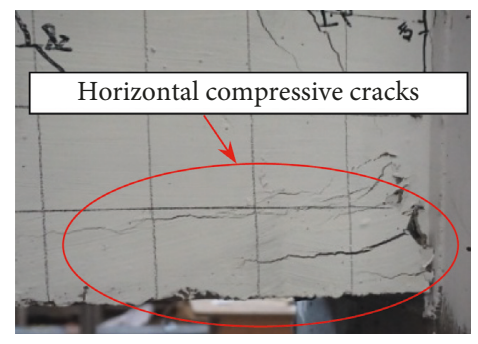

(c)
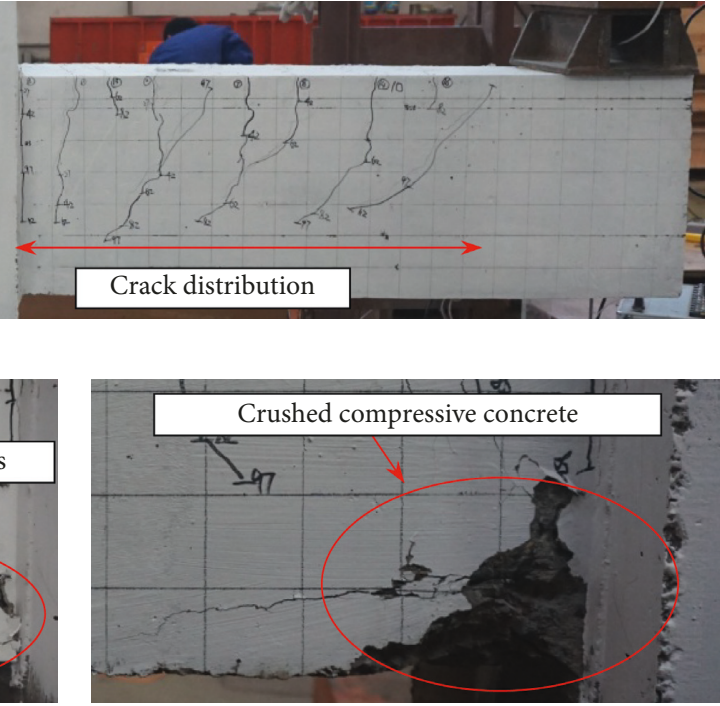

(d)

FIGURE 7: Photographs from the experimental study. (a) Crack distribution in the shear span. (b) First crack at the section adjacent to the beam-column connection. (c) Horizontal compressive cracks developed at the compressive zone. (d) Compressive concrete was obviously crushed.

$$
\theta_{\text {slip }}=\frac{s}{d-x_{c}}
$$

where $d$ is the effective depth of the section and $x_{c}$ is the depth of the neutral axis.

As shown in Figure 10(a), the local slip at the midpoint of the straight embedment reinforcement through the interior beam-column connection is zero when symmetrical loads are applied to the beam end. The embedment reinforcement can be considered to sustain the reverse symmetrical tensile force from the midpoint. If the concrete deformation is ignored, the slippage of the reinforcement $s$ can be calculated by integrating the strain along half of the embedment length:

$$
s=\int_{0}^{l_{\mathrm{ah}}} \varepsilon_{\mathrm{s}}(x) d x,
$$

where $l_{\mathrm{ah}}$ is half of the embedment length of the continuous reinforcement through the interior beam-column connection and $\varepsilon_{\mathrm{s}}$ is the rebar strain. 
TABLE 4: Load of the interior beam-column connection at characteristic points.

\begin{tabular}{lccccccccc}
\hline & \multicolumn{3}{c}{$\begin{array}{c}\text { Crack load } \\
\text { Specimen No. }\end{array}$} & \multicolumn{2}{c}{$\begin{array}{c}\text { Yield } \\
\text { load }(\mathrm{kN})\end{array}$} & \multicolumn{3}{c}{$\begin{array}{c}\text { Nominal } \\
\text { ultimate } \\
\text { load }(\mathrm{kN})\end{array}$} & \multicolumn{2}{c}{$\begin{array}{c}\text { Peak load } \\
(\mathrm{kN})\end{array}$} \\
& $\mathrm{E}$ & $\mathrm{W}$ & $\mathrm{E}$ & $\mathrm{W}$ & $\mathrm{E}$ & $\mathrm{W}$ & $\mathrm{E}$ & $\mathrm{W}$ \\
\hline IA-400-C40-18 & 19.5 & 24 & 107 & 102 & 127 & 127 & 129 & 129 \\
IA-400-C50-18 & 25.5 & 25.5 & 115 & 100 & 135 & 135 & 135 & 135 \\
IA-400-C60-18 & 24 & 21 & 113 & 117 & 127 & 129 & 129 & 130 \\
IA-600-C40-20 & 15 & 15 & 109 & 113 & 121 & 121 & 127 & 125 \\
IA-600-C50-20 & 25.5 & 32 & 177 & 182 & 192 & 192 & 202 & 192 \\
IA-600-C60-20 & 24 & 27 & 160 & 160 & 180 & 180 & 175 & 177 \\
IA-800-C40-22 & 21 & 21 & 116 & 122 & 140 & 137 & 145 & 146 \\
IA-800-C50-22 & 21 & 21 & 127 & 122 & 142 & 142 & 147 & 150 \\
IA-800-C60-22 & 21 & 19.5 & 170 & 170 & 211 & 208 & 221 & 213 \\
IB-400-C40-18 & 18 & 18 & 122 & 122 & 152 & 152 & 157 & 156 \\
IB-400-C50-18 & 21 & 21 & 130 & 140 & 150 & 150 & 156 & 159 \\
IB-400-C60-18 & 19.5 & 19.5 & 130 & 130 & 155 & 155 & 162 & 160 \\
IB-600-C40-20 & 18 & 18 & 115 & 115 & 139 & 135 & 140 & 140 \\
IB-600-C50-20 & 18 & 18 & 114 & 104 & 134 & 134 & 142 & 134 \\
IB-600-C60-20 & 24 & 24 & 170 & 160 & 205 & 200 & 220 & 208 \\
IB-800-C40-22 & 16.5 & 15 & 137 & 142 & 157 & 157 & 167 & 168 \\
IB-800-C50-22 & 18 & 18 & 142 & 142 & 175 & 167 & 184 & 174 \\
IB-800-C60-22 & 22.5 & 22.5 & 130 & 120 & 165 & 165 & 175 & 165 \\
\hline E & & & & &
\end{tabular}

E represents the east span of the interior beam-column connection, and $W$ represents the west span of the interior beam-column connection.

TABLE 5: Load of the exterior beam-column connection at characteristic points.

\begin{tabular}{lcccc}
\hline Specimen No. & $\begin{array}{c}\text { Crack } \\
\text { load (kN) }\end{array}$ & $\begin{array}{c}\text { Yield } \\
\text { load } \\
(\mathrm{kN})\end{array}$ & $\begin{array}{c}\text { Nominal } \\
\text { ultimate } \\
\text { load }(\mathrm{kN})\end{array}$ & $\begin{array}{c}\text { Peak } \\
\text { load }(\mathrm{kN})\end{array}$ \\
\hline EA-430-C40-18 & 22.5 & 122.0 & 137.0 & 140.0 \\
EA-380-C50-18 & 18.0 & 124.0 & 140.0 & 146.0 \\
EA-420-C50-20 & 21.0 & 160.0 & 180.0 & 188.0 \\
EA-350-C60-18 & 21.0 & 91.0 & 136.0 & 158.0 \\
EA-330-C40-20 & 18.0 & 102.0 & 114.0 & 122.8 \\
EA-300-C50-20 & 18.0 & 140.0 & 180.0 & 190.0 \\
EA-270-C60-20 & 24.0 & 125.0 & 170.0 & 171.7 \\
EA-300-C60-22 & 16.5 & 86.0 & 121.0 & 135.0 \\
EA-190-C40-20 & 18.0 & 99.0 & 114.0 & 126.1 \\
EA-210-C40-22 & 18.0 & 122.0 & 137.0 & 137.0 \\
EA-190-C50-22 & 18.0 & 124.0 & 140.0 & 154.1 \\
EA-160-C60-20 & 16.5 & 145.0 & 170.0 & 174.7 \\
EB-420-C40-18 & 27.0 & 150.0 & 170.0 & 176.8 \\
EB-420-C50-18 & 19.5 & 125.0 & 150.0 & 186.0 \\
EB-420-C50-20 & 18.0 & 116.0 & 131.0 & 146.0 \\
EB-400-C60-18 & 22.5 & 150.0 & 170.0 & 175.0 \\
EB-380-C40-20 & 21.0 & 105.0 & 140.0 & 145.0 \\
EB-340-C50-20 & 18.0 & 126.0 & 146.0 & 157.5 \\
EB-310-C60-20 & 21.0 & 180.0 & 215.0 & 215.0 \\
EB-340-C60-22 & 22.5 & 130.0 & 155.0 & 164.0 \\
EB-220-C40-20 & 21.0 & 130.0 & 145.0 & 149.4 \\
EB-230-C40-22 & 16.5 & 130.0 & 150.0 & 170.0 \\
EB-210-C50-22 & 16.5 & 140.0 & 175.0 & 189.0 \\
EB-180-C60-20 & 21.0 & 165.0 & 190.0 & 215.0 \\
\hline
\end{tabular}

As shown in Figure 10(b), when hooked bars are used as longitudinal reinforcements in the exterior beam-column connection, a hook displacement occurs if the straight embedment length of the reinforcement is not sufficient. Hence, the slippage of the reinforcement $s$ is the sum of the integral of the strain along the straight embedment length and the hook displacement as expressed in the following equation:

$$
s=\int_{0}^{l_{\mathrm{ah}}} \varepsilon_{\mathrm{s}}(x) d x+\delta_{\mathrm{h}}
$$

where $l_{\mathrm{ah}}$ is the straight lead length of the hooked bar and $\delta_{\mathrm{h}}$ is the hook displacement.

A model for the relationship between force resisted by the hook and hook displacement was proposed by Soroushian et al. [22] based on the experiments for the tensile behaviour of hook bars as shown in the following expressions:

$$
\begin{aligned}
P_{\mathrm{h}} & =P_{\mathrm{hu}}\left(\frac{\delta_{\mathrm{h}}}{2.54}\right), \\
P_{\mathrm{hu}} & =271\left(0.05 d_{\mathrm{b}}-0.25\right), \\
P_{\mathrm{hf}} & =0.54 P_{\mathrm{hu}} .
\end{aligned}
$$

The model shown in Figure 11 is adopted here for predicting the hook displacement $\delta_{\mathrm{h}}$. The force resisted by the hook $P_{\mathrm{h}}$ can be calculated from the experimental results of the rebar strain at the free end of anchorage reinforcement combined with the stress-strain relationship of the reinforcement. Then, the hook displacement $\delta_{\mathrm{h}}$ can be obtained using equations (4)-(6). Figure 12 shows the relationship between the relative straight embedment length $l_{\mathrm{ah}} / d_{\mathrm{b}}$ and the ratio of the hook displacement $\delta_{\mathrm{h}}$ to slippage $s$ at the yielding and nominal ultimate limit states for each exterior beam-column connection. It can be seen that $\delta_{h} / s$ decreases with the increase in $l_{\mathrm{ah}} / d_{\mathrm{b}}$. The fitting curve shows that the ratio $\delta_{h} / s$ does not exceed 0.1 when $l_{\text {ah }}$ is greater than $12 d_{\mathrm{b}}$, which indicates that the effect of the hook displacement $\delta_{\mathrm{h}}$ on $s$ is negligible. The straight embedment length of the hooked bar or headed bar $l_{\text {ah }}$ has been specified in most design specifications, as listed in Table 6. It can be known that the condition $l_{\mathrm{ah}}<12 d_{\mathrm{b}}$ rarely occurs in practice, thus the influence of $\delta_{\mathrm{h}}$ is not considered in this paper. Similar to the hooked bars, when the headed bars are used as longitudinal reinforcements, the slip at the headed end of the bars is negligible.

Based on the tensile strain distribution of the embedment reinforcement obtained from the test, the additional fixed-end rotation of the exterior and interior beam-column connections at the yielding and nominal ultimate limit states can be calculated by combining equations (1)-(3). The results are listed in Tables 7 and 8.

\section{Parametric Study}

A systematic parametric study on the additional fixed-end rotation at the yielding and nominal ultimate states was conducted based on the experimental results. The parameters that potentially affect the bond between concrete and reinforcement are explored, including the yield strength of 

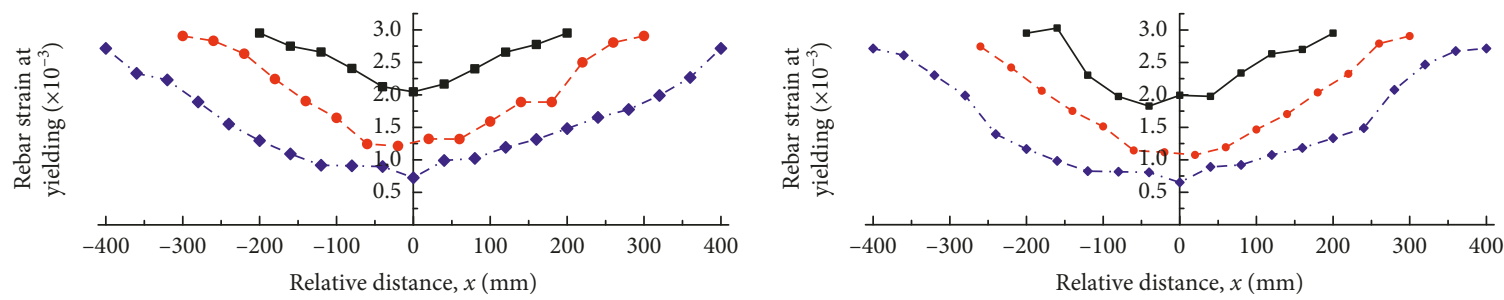

$$
\begin{aligned}
& \longrightarrow \text { IA-400-C40-18 } \\
& -\bullet \text { IA-600-C40-20 } \\
& -\bullet \text { IA-800-C40-22 }
\end{aligned}
$$
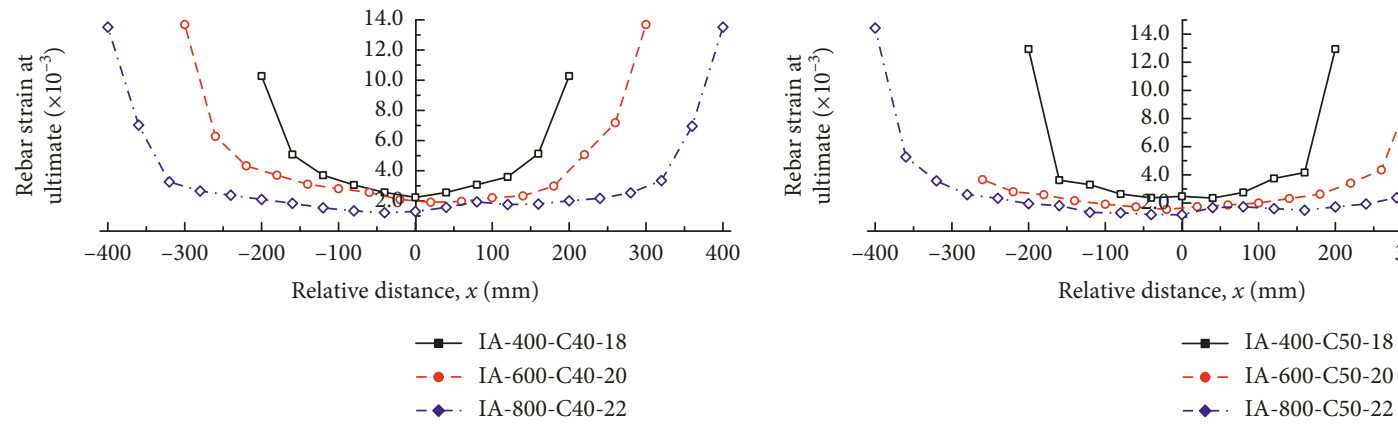

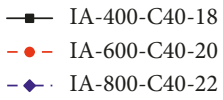

(a)

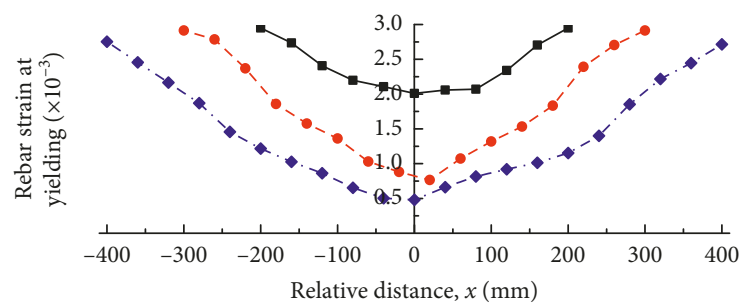

$\rightarrow$ IA-400-C60-18

- - IA-600-C60-20

- • IA-800-C60-22

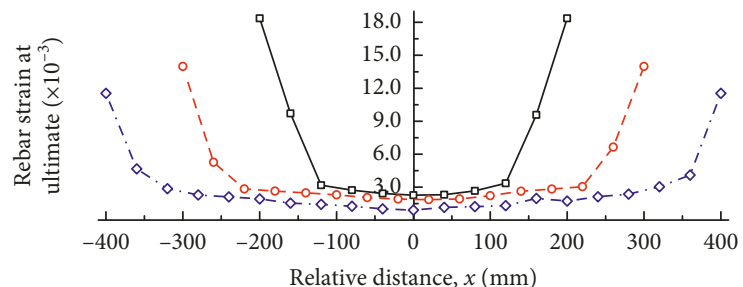

- IA-400-C60-18

- - IA-600-C60-20

- •. IA- $800-\mathrm{C} 60-22$ (b)

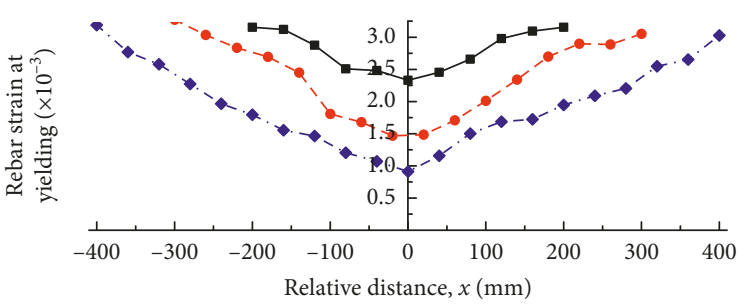

$\rightarrow$ IB-400-C40-18

- - IB-600-C40-20

- . IB-800-C40-22

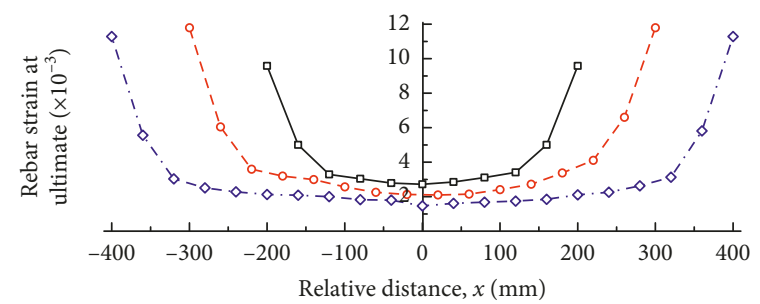

$\rightarrow$ IB-400-C40-18

- - IB-600-C40-20

- • . IB-800-C40-22

(d)

Figure 8: Continued. 

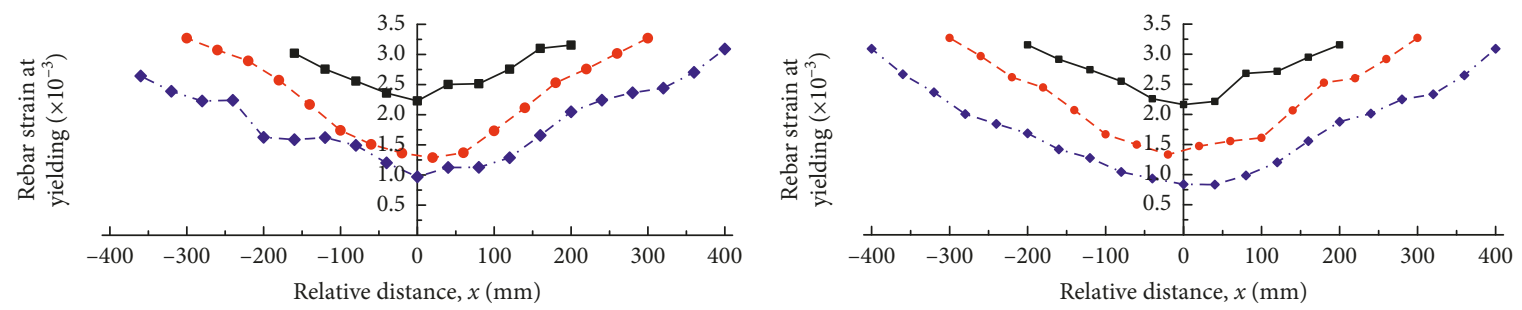

$\rightarrow-$ IB-400-C50-18

- - IB-600-C50-20

- . IB-800-C50-22
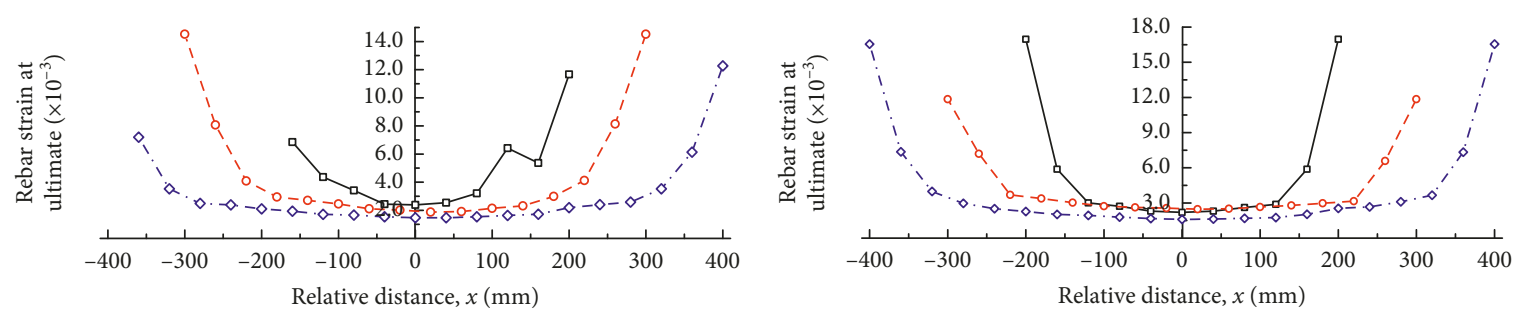

$$
\begin{aligned}
& \longrightarrow \text { IB-400-C50-18 } \\
& -\bullet \text { IB-600-C50-20 } \\
& -\bullet \text { IB-800-C50-22 }
\end{aligned}
$$

(e) $\rightarrow$ IB-400-C60-18

$-\bullet$ IB-600-C60-20

- • IB-800-C60-22

$\rightarrow$ IB-400-C60-18

- - IB-600-C60-20

- IB-800-C60-22

(f)

FIGURE 8: Strain distribution along the tensile reinforcement throughout the interior beam-column connection. Specimen type: (a) IA-C40; (b) IA-C50; (c) IA-C60; (d) IB-C40; (e) IB-C50; (f) IB-C60.
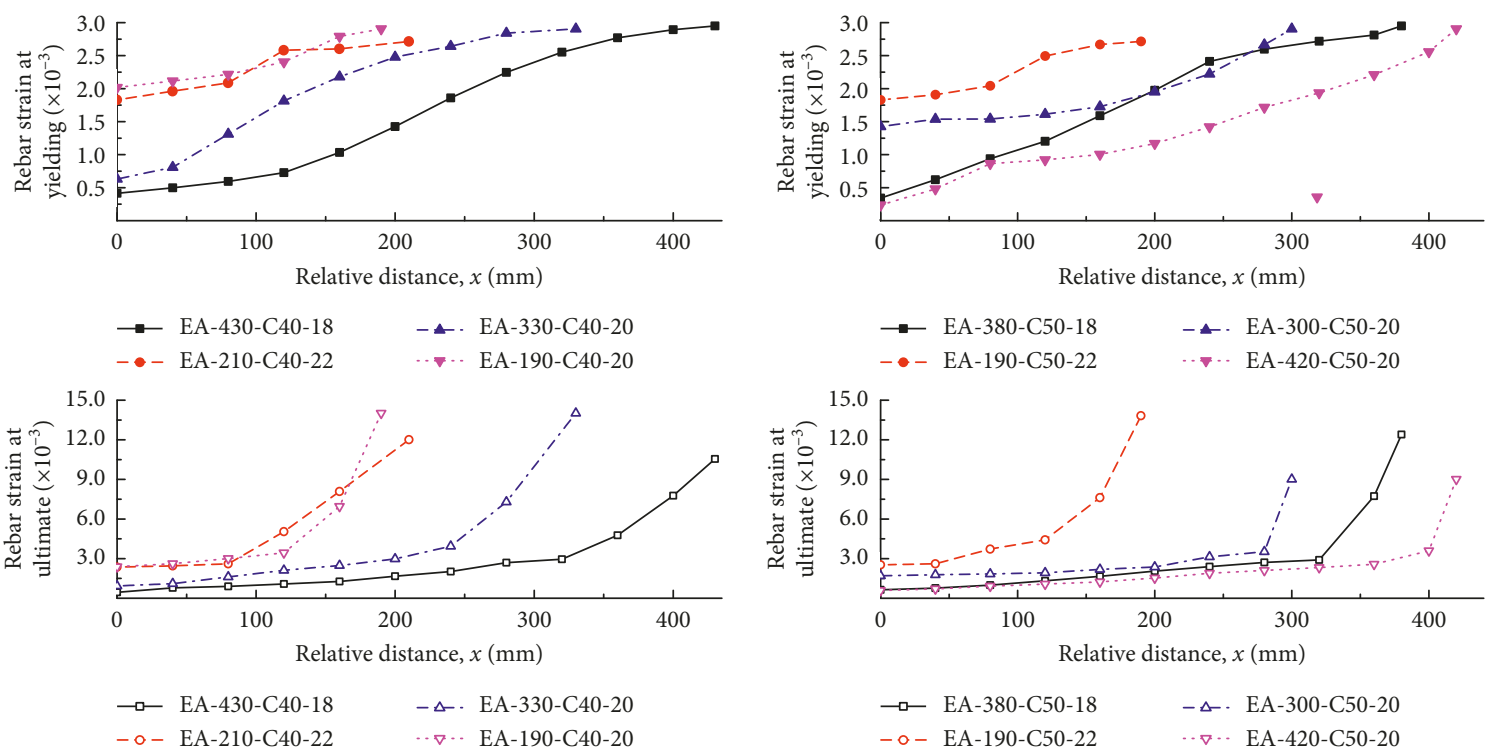

(a)

(b)

Figure 9: Continued. 

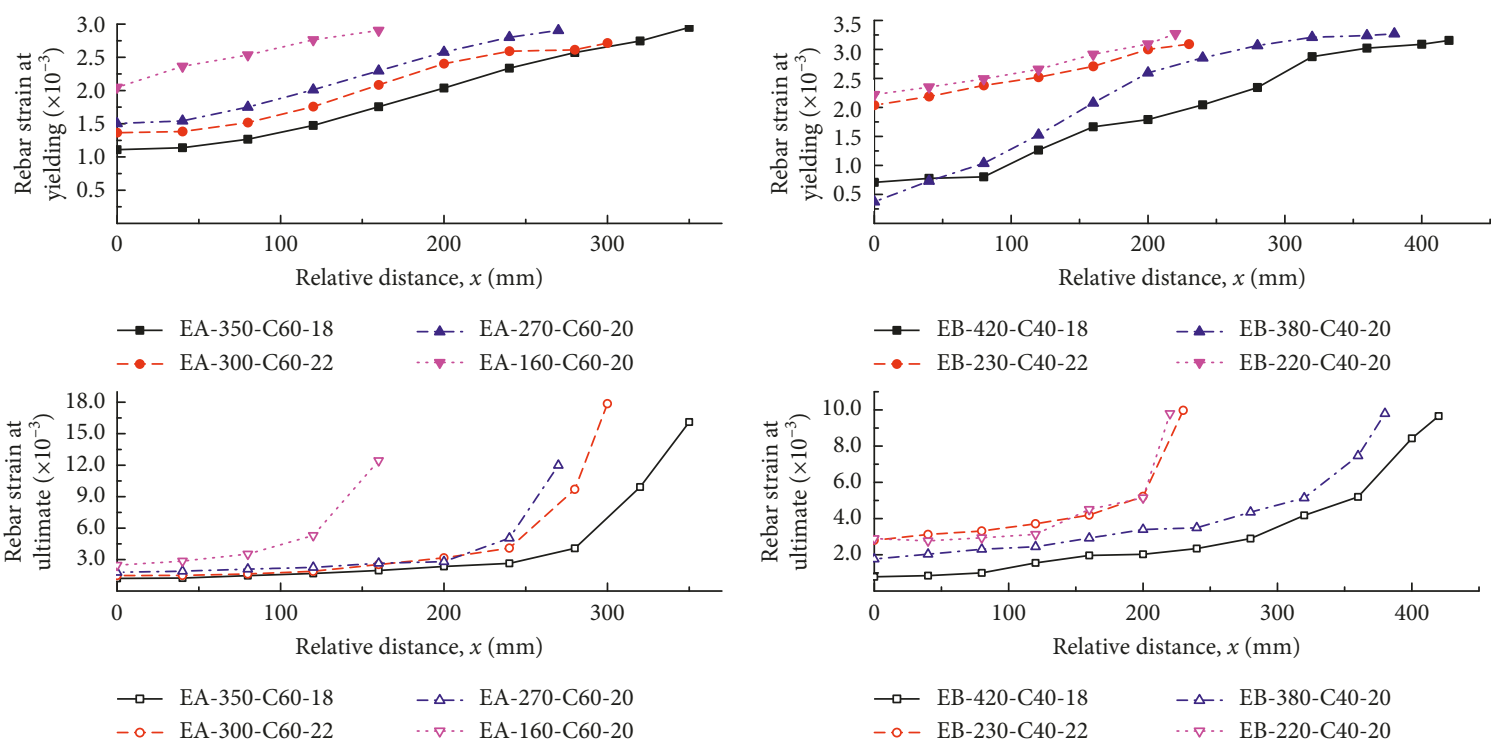

(c)
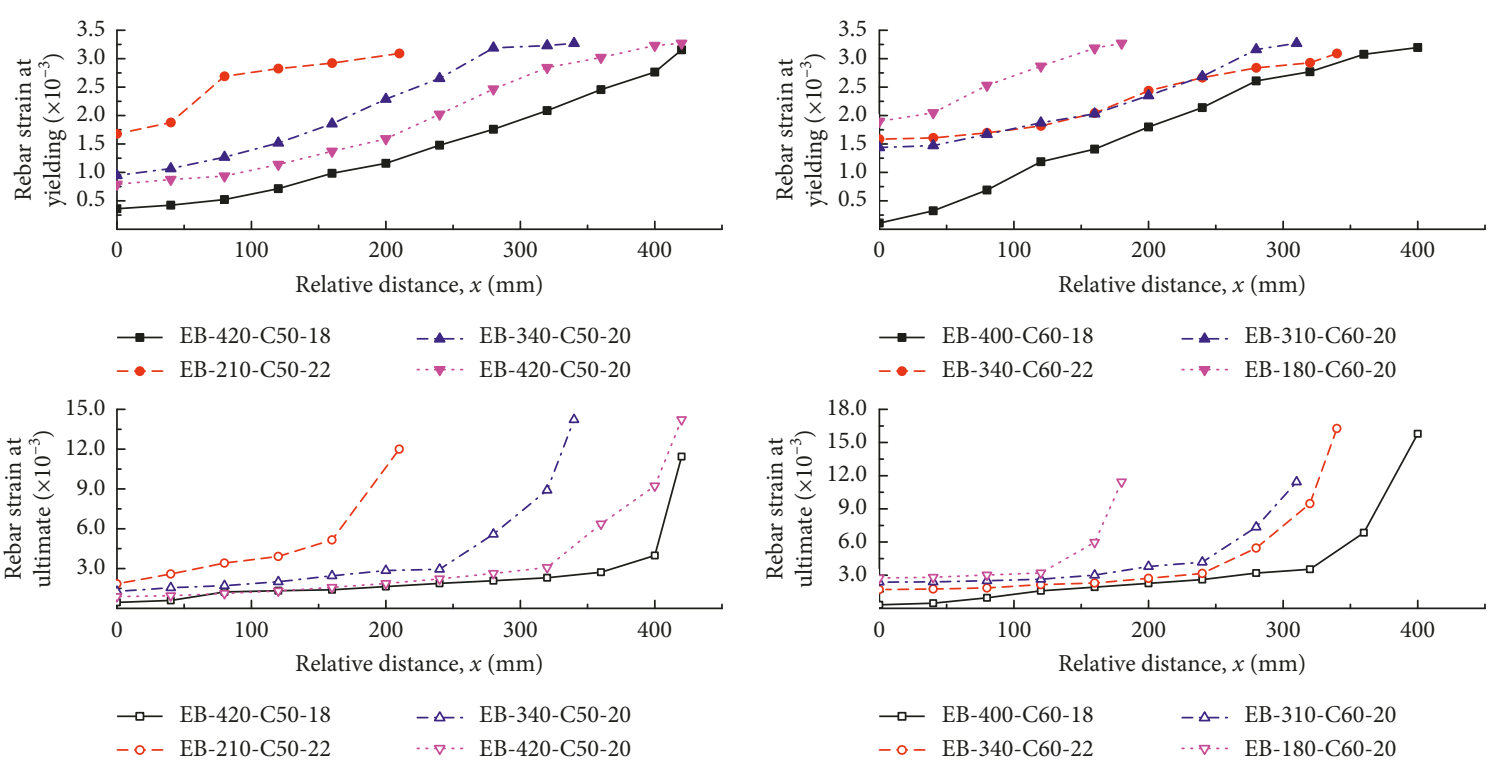

(e)

(f)

FIGURE 9: Strain distribution along the tensile reinforcement anchored in the exterior beam-column connection. Specimen type: (a) EAC40; (b) EA-C50; (c) EA-C60; (d) EB-C40; (e) EB-C50; (f) EB-C60.

the steel bar $f_{\mathrm{y}}$, concrete tensile strength $f_{\mathrm{ct}}$, diameter $d_{\mathrm{b}}$, and straight embedment length $l_{\mathrm{ah}}$ of the reinforcement in the beam-column connection. Moreover, the depth of the neutral axis is taken into consideration, as it considerably affects the depth of the tensile zone and slippage of the embedment reinforcement at the critical section. When one parameter is studied, the other parameters are kept constant. Despite a certain fluctuation in the test results, the clear trends of the influence of each parameter are obtained.

4.1. Effect of Reinforcement Diameter. The diameter of the reinforcement $d_{\mathrm{b}}$ is the main factor that affects the additional fixed-end rotation due to the strain penetration. As shown in
Figure 13, consider the case where a reinforcing bar with a diameter $d_{\mathrm{b}}$ is anchored in concrete and a tensile force is applied at the loading end. The equilibrium equation for the bar with sufficient length is as follows:

$$
F_{\mathrm{t}}=\int_{0}^{L_{\mathrm{d}}} \pi d_{\mathrm{b}} \cdot \tau_{\mathrm{s}}(x) d x .
$$

The rebar strain decreases along the development length because of the bond force between the concrete and reinforcement. For a constant tensile force, an increase in $d_{\mathrm{b}}$ leads to an increase in the bond surface area. Consequently, the bond force between the concrete and reinforcement decreases. Therefore, a slower reduction in the reinforcement stress occurs along the anchorage length. This 


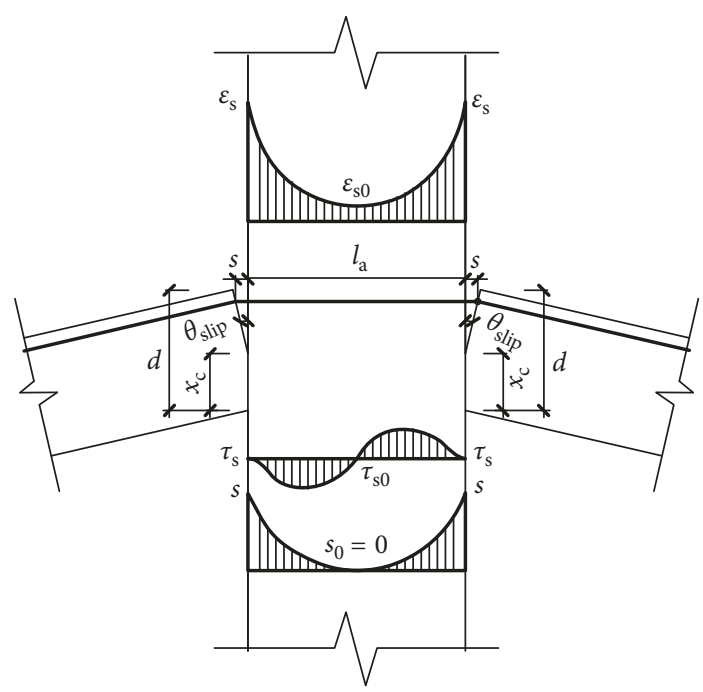

(a)

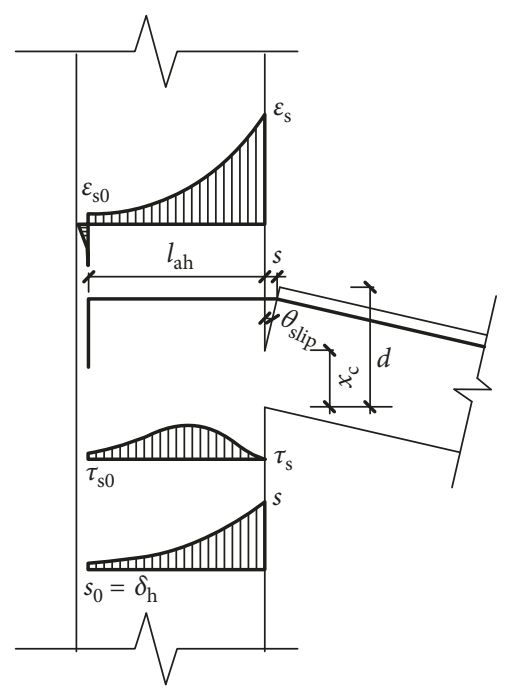

(b)

FIGURE 10: Strain penetration of the longitudinal tensile reinforcement inside (a) interior beam-column connection and (b) exterior beamcolumn connection.

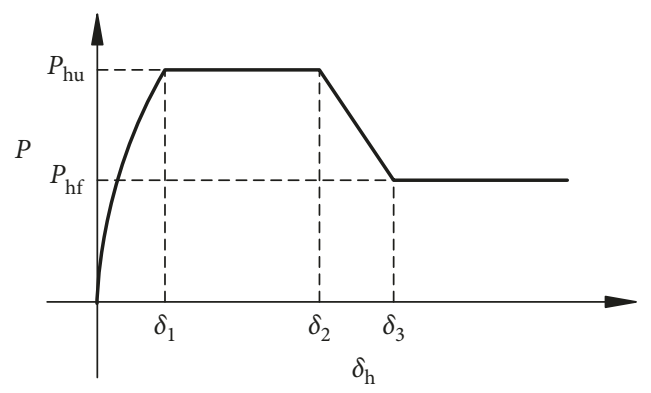

FIgURE 11: Hook force-hook deformation relationship.

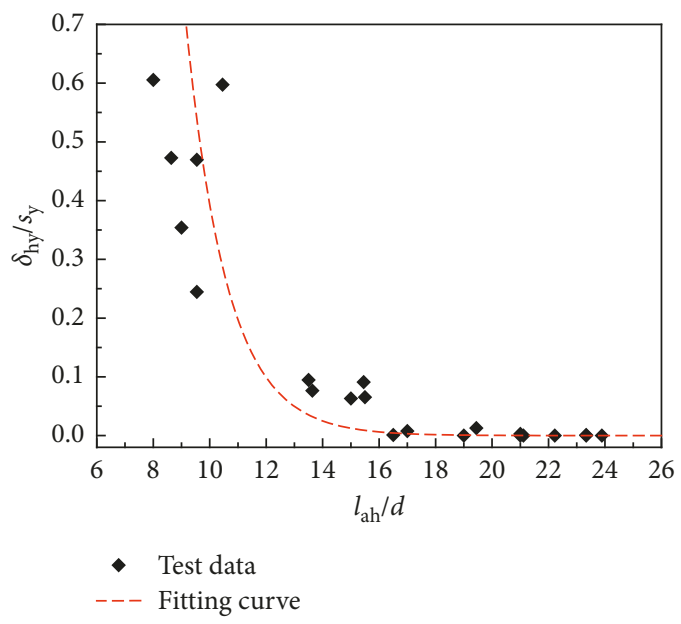

(a)

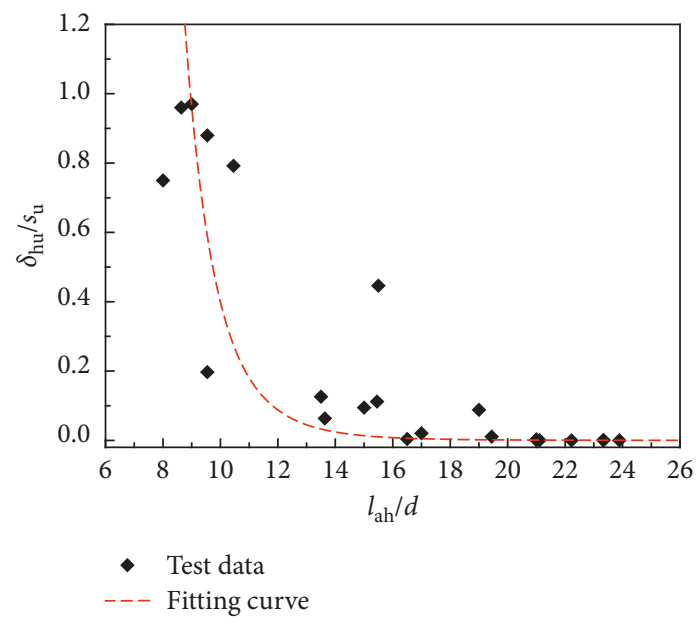

(b)

Figure 12: Relationship between $l_{\mathrm{ah}} / d_{\mathrm{b}}$ and $\delta_{\mathrm{h}} / s$ : (a) at the yielding state; (b) at the nominal ultimate state.

implies that an increase in $d_{\mathrm{b}}$ increases the extent of yield penetration and is advantageous for increasing the additional fixed-end rotation. Generally, the effect of strain penetration is indirectly reflected in the strain penetration length. Tastani and Pasntazopoulou [13] established an analytical expression for the strain penetration length $l_{\mathrm{sp}}$, in 
TABLE 6: Design specifications for straight anchorage length of hooked or headed bar.

\begin{tabular}{|c|c|c|}
\hline Code & $\begin{array}{l}\text { Straight anchorage length of } \\
\text { hooked or headed bar, } l_{\mathrm{ah}}\end{array}$ & Commentary \\
\hline ACI 318-14 [21] & $\begin{array}{ll}l_{\mathrm{ah}} \geq 0.02 \psi_{\mathrm{e}}\left(f_{\mathrm{y}} / \lambda \sqrt{f_{\mathrm{c}}^{\prime}}\right) d_{\mathrm{b}} \quad \text { for hooked bar } \\
l_{\mathrm{ah}} \geq 0.016 \psi_{\mathrm{e}}\left(f_{\mathrm{y}} / \lambda \sqrt{f_{\mathrm{c}}^{\prime}}\right) d_{\mathrm{b}} \quad \text { for headed bar }\end{array}$ & $\begin{array}{c}\psi_{\mathrm{e}}=1.2 \text { for epoxy-coated reinforcement; } \psi_{\mathrm{e}}=1.0 \text { for other cases; } \\
\lambda=0.75 \text { for lightweight concrete; } \lambda=1.0 \text { for other cases. }\end{array}$ \\
\hline $\begin{array}{l}\text { Chinese code } \\
\text { (GB 50010-2010) [20] }\end{array}$ & $\begin{array}{c}l_{\mathrm{ah}} \geq 0.4 l_{\mathrm{ab}} \\
l_{\mathrm{ab}}=\alpha\left(f_{\mathrm{y}} / f_{\mathrm{t}}\right) d_{\mathrm{b}}\end{array}$ & $\begin{array}{l}f_{\mathrm{y}} \text { is the design value of the reinforcement tensile strength; } \\
f_{\mathrm{t}} \text { is the design value of the concrete tensile strength; } \\
\alpha=0.14 \text { for deformed bar; } \alpha=0.16 \text { for plain bar. }\end{array}$ \\
\hline $\begin{array}{l}\text { Eurocode } \\
\text { 2-part 1-1 [23] }\end{array}$ & $\begin{aligned} l_{\mathrm{ah}} & \geq \alpha_{1} l_{\mathrm{b}, \mathrm{rqd}} \\
l_{\mathrm{b}, \mathrm{rqd}} & =\left(d_{\mathrm{b}} \sigma_{\mathrm{sd}} / 4 f_{\mathrm{bd}}\right) \\
f_{\mathrm{bd}} & =2.25 \eta_{1} \eta_{2} f_{\mathrm{t}}\end{aligned}$ & $\begin{array}{l}\alpha_{1}=0.7 \text { if } c_{\mathrm{d}}>3 d_{\mathrm{b}} \text {; otherwise } \alpha_{1}=1.0 ; \\
\sigma_{\mathrm{sd}} \text { is the design stress of the bar at the position from where the } \\
\text { anchorage is measured; } \\
\eta_{1}=1.0 \text { when "good" conditions are obtained; } \\
\eta_{1}=0.7 \text { for other cases; } \eta_{2}=1.0 \text { for } d_{\mathrm{b}} \leq 32 \mathrm{~mm} ; \eta_{2}=\left(132-d_{\mathrm{b}}\right) / 100 \\
\text { for } d_{\mathrm{b}}>32 \mathrm{~mm} .\end{array}$ \\
\hline
\end{tabular}

TABLE 7: Additional fixed-end rotation of interior beam-column connection at yielding and nominal ultimate limit states.

\begin{tabular}{|c|c|c|c|c|c|c|c|c|}
\hline \multirow{2}{*}{ Specimen no. } & \multicolumn{2}{|c|}{$s_{\mathrm{y}}(\mathrm{mm})$} & \multicolumn{2}{|c|}{$\theta_{\mathrm{y}, \mathrm{slip}}\left(\times 10^{-3} \mathrm{rad}\right)$} & \multicolumn{2}{|c|}{$s_{\mathrm{u}}(\mathrm{mm})$} & \multicolumn{2}{|c|}{$\theta_{\mathrm{u}, \mathrm{slip}}\left(\times 10^{-3} \mathrm{rad}\right)$} \\
\hline & $\mathrm{E}$ & $\mathrm{W}$ & $\mathrm{E}$ & $\mathrm{W}$ & $\mathrm{E}$ & W & $\mathrm{E}$ & $\mathrm{W}$ \\
\hline IA-400-C40-18 & 0.50 & 0.50 & 2.41 & 2.40 & 0.82 & 0.82 & 3.44 & 3.43 \\
\hline IA-400-C50-18 & 0.46 & 0.48 & 2.15 & 2.25 & 0.78 & 0.83 & 3.11 & 3.29 \\
\hline IA-400-C60-18 & 0.48 & 0.47 & 2.13 & 2.09 & 1.08 & 1.06 & 4.03 & 3.96 \\
\hline IA-600-C40-20 & 0.58 & 0.56 & 2.74 & 2.66 & 1.23 & 1.18 & 4.81 & 4.64 \\
\hline IA-600-C50-20 & 0.55 & 0.54 & 2.66 & 2.63 & 0.82 & 0.89 & 3.46 & 3.77 \\
\hline IA- $600-C 60-20$ & 0.52 & 0.51 & 2.42 & 2.39 & 1.02 & 1.09 & 3.99 & 4.25 \\
\hline IA-800-C40-22 & 0.65 & 0.62 & 3.05 & 2.88 & 1.23 & 1.26 & 4.84 & 4.95 \\
\hline IA- $800-C 50-22$ & 0.58 & 0.63 & 2.73 & 2.95 & 1.17 & 1.16 & 4.53 & 4.49 \\
\hline IA-800-C60-22 & 0.55 & 0.56 & 2.68 & 2.73 & 1.01 & 1.01 & 4.11 & 4.10 \\
\hline IB-400-C40-18 & 0.55 & 0.56 & 2.72 & 2.76 & 0.81 & 0.82 & 3.44 & 3.48 \\
\hline IB-400-C50-18 & 0.54 & 0.54 & 2.49 & 2.52 & 0.96 & 0.98 & 3.91 & 3.98 \\
\hline IB-400-C60-18 & 0.53 & 0.53 & 2.36 & 2.38 & 0.94 & 0.93 & 3.55 & 3.52 \\
\hline IB-600-C40-20 & 0.67 & 0.67 & 3.12 & 3.11 & 1.10 & 1.13 & 4.46 & 4.58 \\
\hline IB-600-C50-20 & 0.65 & 0.63 & 2.92 & 2.83 & 1.23 & 1.19 & 4.76 & 4.63 \\
\hline IB-600-C60-20 & 0.62 & 0.63 & 2.88 & 2.90 & 1.19 & 1.11 & 4.82 & 4.50 \\
\hline IB-800-C40-22 & 0.75 & 0.78 & 3.55 & 3.69 & 1.18 & 1.16 & 4.83 & 4.75 \\
\hline IB-800-C50-22 & 0.76 & 0.76 & 3.61 & 3.61 & 1.26 & 1.17 & 5.04 & 4.70 \\
\hline IB-800-C60-22 & 0.69 & 0.71 & 3.05 & 3.13 & 1.42 & 1.42 & 5.40 & 5.39 \\
\hline
\end{tabular}

which the influential factors of strain permeation length were considered comprehensively as follows:

$$
l_{\mathrm{sp}}=\left(\varepsilon_{s 0}-\varepsilon_{\mathrm{sy}}\right) \cdot\left(\frac{d_{\mathrm{b}} E_{\mathrm{sh}}}{4 f_{\mathrm{b}}^{\mathrm{res}}}\right),
$$

where $\varepsilon_{s 0}$ is the rebar strain at the critical section; $\varepsilon_{\text {sy }}$ and $E_{\text {sh }}$ are the yielding strain and hardening modulus of the steel reinforcement; and $f_{\mathrm{b}}$ res is the residual bond strength between the concrete and reinforcement. From equation (8), it can be known the effect of $d_{\mathrm{b}}$ on the strain penetration shows a linear relationship. There are also several empirical expressions of the strain penetration length, which have the same variation trend about the diameter, as listed in Table 9. In this paper, the variation in the additional fixed-end rotation with respect to $d_{\mathrm{b}}$ is considered to be consistent with previous studies.

4.2. Effect of the Neutral Axis Depth. The effect of neutral axis depth $x_{\mathrm{c}}$ on the additional fixed-end rotation should be considered in that it is related to both depth of the tensile zone and slippage of reinforcement at the critical section. To facilitate the application of design, the ratio $\xi=\lambda x_{\mathrm{c}, \mathrm{u}} / d$ is investigated in this paper, where $x_{\mathrm{c}, \mathrm{u}}$ is the depth of the neutral axis when the strain in the extreme compressed fibre of the critical section reaches the ultimate strain, $d$ is the effective depth of the section, and $\lambda$ is a factor specified in the design code [23].

The depth of the neutral axis $x_{\mathrm{c}}$ can be calculated based on the two conditions of static equilibrium and strain compatibility of the critical section. Figure 14 presents the critical cross section reinforced with tensile and compressive steel bars, which is divided into a number of layers. According to the assumption that the strain in each layer is linearly proportional to its distance from the neural axis (Figure 14(b)) [21], as expressed in equation (9), the stresses in each layer can be obtained from the stressstrain relationships of the concrete and reinforcement. Then, the equilibrium between the compressive and tensile forces acting on the cross section shown in Figure 14(c) can be expressed by equation (10): 
TABLE 8: Additional fixed-end rotation of exterior beam-column connection at yielding and nominal ultimate states.

\begin{tabular}{|c|c|c|c|c|}
\hline Specimen no. & $s_{\mathrm{y}}(\mathrm{mm})$ & $\theta_{\mathrm{y}, \mathrm{slip}}\left(\times 10^{-3} \mathrm{rad}\right)$ & $s_{\mathrm{u}}(\mathrm{mm})$ & $\theta_{\mathrm{u}, \text { slip }}\left(\times 10^{-3} \mathrm{rad}\right)$ \\
\hline EA-430-C40-18 & 0.70 & 3.37 & 1.16 & 4.83 \\
\hline EA-380-C50-18 & 0.68 & 3.28 & 1.23 & 4.94 \\
\hline EA-420-C50-20 & 0.78 & 3.90 & 1.26 & 5.43 \\
\hline EA-350-C60-18 & 0.67 & 2.98 & 1.23 & 4.68 \\
\hline EA-330-C40-20 & 0.69 & 3.24 & 1.27 & 4.95 \\
\hline EA-300-C50-20 & 0.67 & 3.36 & 1.09 & 4.70 \\
\hline EA-270-C60-20 & 0.58 & 2.72 & 1.03 & 4.11 \\
\hline EA-300-C60-22 & 0.62 & 2.77 & 1.09 & 4.09 \\
\hline EA-190-C40-20 & 0.46 & 2.14 & 0.88 & 3.45 \\
\hline EA-210-C40-22 & 0.43 & 2.10 & 0.80 & 3.22 \\
\hline EA-190-C50-22 & 0.43 & 2.00 & 0.95 & 3.74 \\
\hline EA-160-C60-20 & 0.43 & 2.00 & 0.77 & 3.08 \\
\hline EB-420-C40-18 & 0.80 & 3.84 & 1.25 & 5.28 \\
\hline EB-420-C50-18 & 0.77 & 3.60 & 1.25 & 5.10 \\
\hline EB-420-C50-20 & 0.80 & 3.80 & 1.28 & 5.00 \\
\hline EB-400-C60-18 & 0.71 & 3.17 & 1.26 & 4.81 \\
\hline EB-380-C40-20 & 0.82 & 3.92 & 1.40 & 5.91 \\
\hline EB-340-C50-20 & 0.70 & 3.15 & 1.20 & 4.67 \\
\hline EB-310-C60-20 & 0.67 & 3.11 & 1.22 & 4.95 \\
\hline EB-340-C60-22 & 0.75 & 3.34 & 1.26 & 4.78 \\
\hline EB-220-C40-20 & 0.59 & 2.81 & 1.09 & 4.61 \\
\hline EB-230-C40-22 & 0.58 & 2.86 & 0.96 & 4.03 \\
\hline EB-210-C50-22 & 0.54 & 2.55 & 0.97 & 3.89 \\
\hline EB-180-C60-20 & 0.50 & 2.30 & 0.80 & 3.24 \\
\hline
\end{tabular}

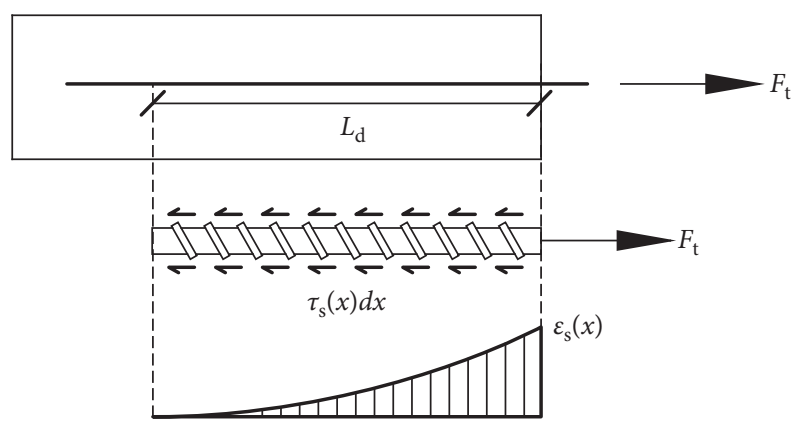

FIGURE 13: Equilibrium of the anchorage reinforcement with development length $L_{\mathrm{d}}$.

TABLe 9: Empirical expressions of strain penetration length $L_{\mathrm{sp}}$.

\begin{tabular}{lc}
\hline Reference & Strain penetration length, $L_{\mathrm{sp}}$ \\
\hline Paulay and Priestley [19] & $L_{\mathrm{sp}}=0.022 f_{\mathrm{y}} d_{\mathrm{b}}$ \\
Priestley and Park [24] & $L_{\mathrm{sp}}=6 d_{\mathrm{b}}$ \\
Panagiotakos and Fardis [25] & $L_{\mathrm{sp}}=0.021 f_{\mathrm{y}} d_{\mathrm{b}}$ \\
& $L_{\mathrm{sp}}=0.24\left(f_{\mathrm{y}} / \sqrt{f_{\mathrm{c}}^{\prime}}\right) d_{\mathrm{b}}$ \\
Eurocode 8-part 3 [26] & $L_{\mathrm{sp}}=0.11\left(f_{\mathrm{y}} / \sqrt{f_{\mathrm{c}}^{\prime}}\right) d_{\mathrm{b}}$ \\
\hline
\end{tabular}

$$
\begin{aligned}
\varepsilon_{i} & =\frac{x_{\mathrm{c}}-x_{\mathrm{i}}}{d-x_{\mathrm{c}}} \varepsilon_{\mathrm{s}}, \\
\int_{0}^{d} b \cdot f_{c}\left(\varepsilon_{i}\right) d x+E_{\mathrm{s}}^{\prime} \varepsilon_{\mathrm{s}}^{\prime} A_{\mathrm{s}}^{\prime} & =E_{\mathrm{s}} \varepsilon_{\mathrm{s}} A_{\mathrm{s}},
\end{aligned}
$$

where $b$ is the width of the section, $f_{c}(x)$ is the function of the concrete stress-strain relationship, $E_{\mathrm{s}}$ and $E_{\mathrm{s}}^{\prime}$ are the tensile and compressive modulus of the reinforcement, respectively.

Combining the test results of the rebar strains with equations (9)-(10), the depth of the neutral axes $x_{c, y}$ and $x_{c, u}$ can be calculated, and the relationships between $\xi$ and depth of the tensile zones $x_{\mathrm{t}, \mathrm{y}}$ and $x_{\mathrm{t}, \mathrm{u}}$ can be obtained as shown in Figure 15. The expressions of the fitting curves are as follows:

$$
\begin{aligned}
& x_{\mathrm{t}, \mathrm{y}}=d-x_{\mathrm{c}, \mathrm{y}}=0.8 d(1-0.95 \xi), \\
& x_{\mathrm{t}, \mathrm{u}}=d-x_{\mathrm{c}, \mathrm{u}}=d(1-1.25 \xi) .
\end{aligned}
$$

It is simple to understand that $x_{\mathrm{t}}$ clearly decreases with the increase in $\xi$. The key problem here is to investigate the effect of $\xi$ on the slippage of the reinforcement. To eliminate the effects of the rebar diameters, the yield strength of reinforcement, and the concrete tensile strength on the slippage of different test specimens, the coefficient $\delta_{1}=d_{\mathrm{b}}\left(f_{\mathrm{y}} / f_{\mathrm{ct}}\right)$ was introduced. Three comparison groups were chosen from the test results, in which the relative embedment length $l_{\mathrm{ah}} / d_{\mathrm{b}}$ in the beam-column connections was similar. For the yielding state, the relationship between $s_{y} / \delta_{1}$ and $\xi$ is shown in Figure $16(\mathrm{a})$. It can be seen that $s_{\mathrm{y}} / \delta_{1}$ is largely constant in each comparison group for $\xi$ varying from 0.11 to 0.21 , which means that the influence of $\xi$ on $s_{\mathrm{y}}$ is almost negligible. Combining equations (1) and (11), we see that an increase in $\xi$

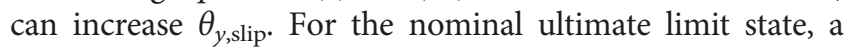
reduction tendency of the power function $s_{\mathrm{u}} / \delta_{1}$ is observed with the increase in $\xi$, as shown in Figure 16(b). The slippage is obtained by integrating the strain that gradually decreases along the embedment length, and the strain at the critical 


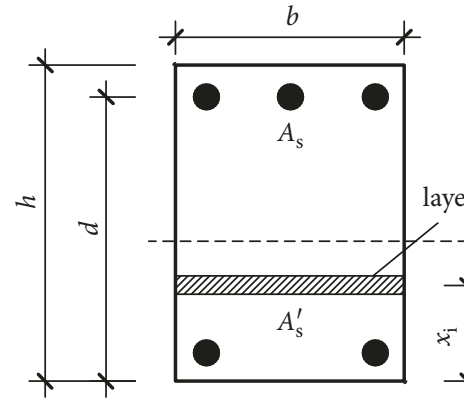

(a)

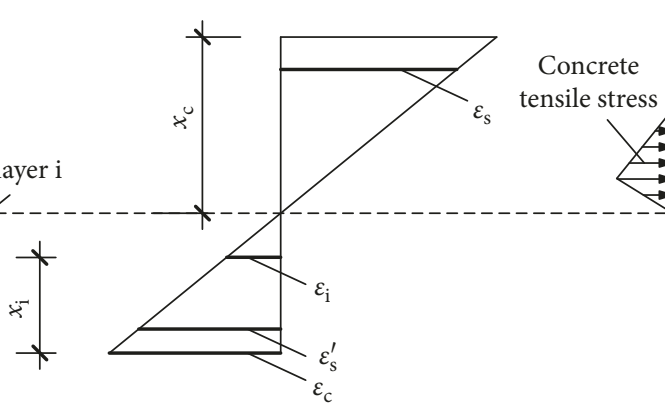

(b)

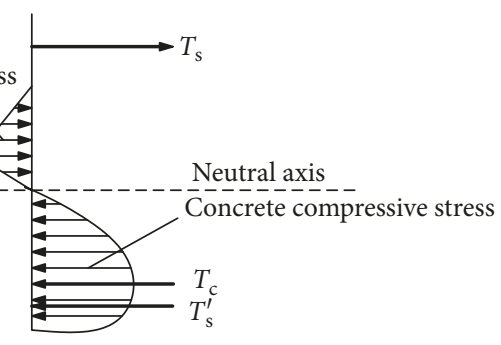

(c)

Figure 14: Force equilibrium of the reinforced concrete section. (a) Critical cross section. (b) Strain distribution. (c) Stress distribution.

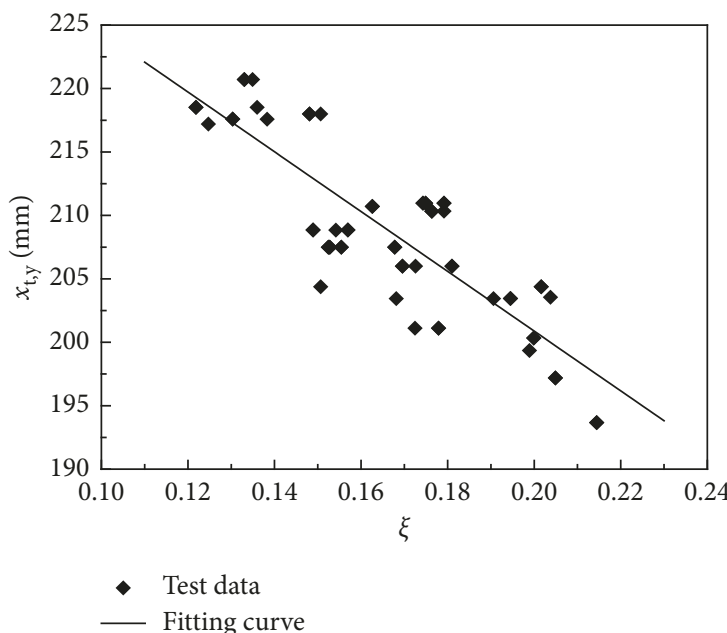

(a)

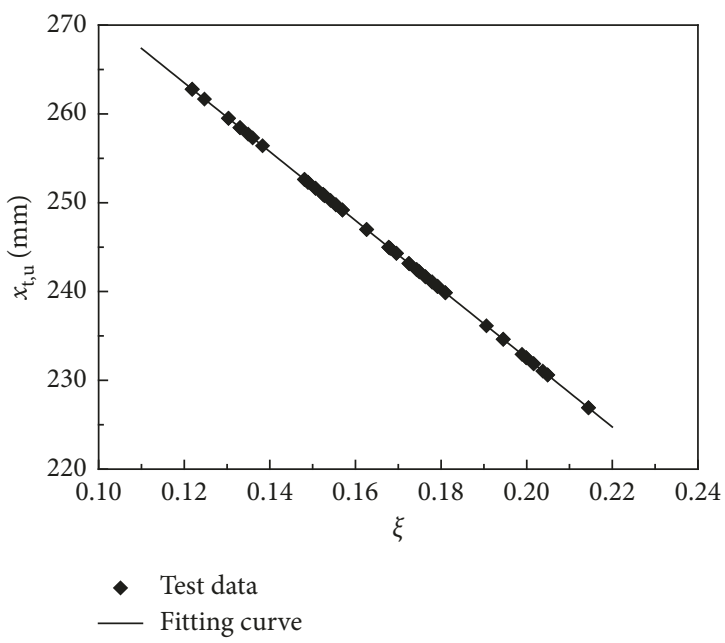

(b)

FIGURE 15: Relationship between $\xi$ and $x_{\mathrm{t}}$ at (a) yielding and (b) nominal ultimate states.
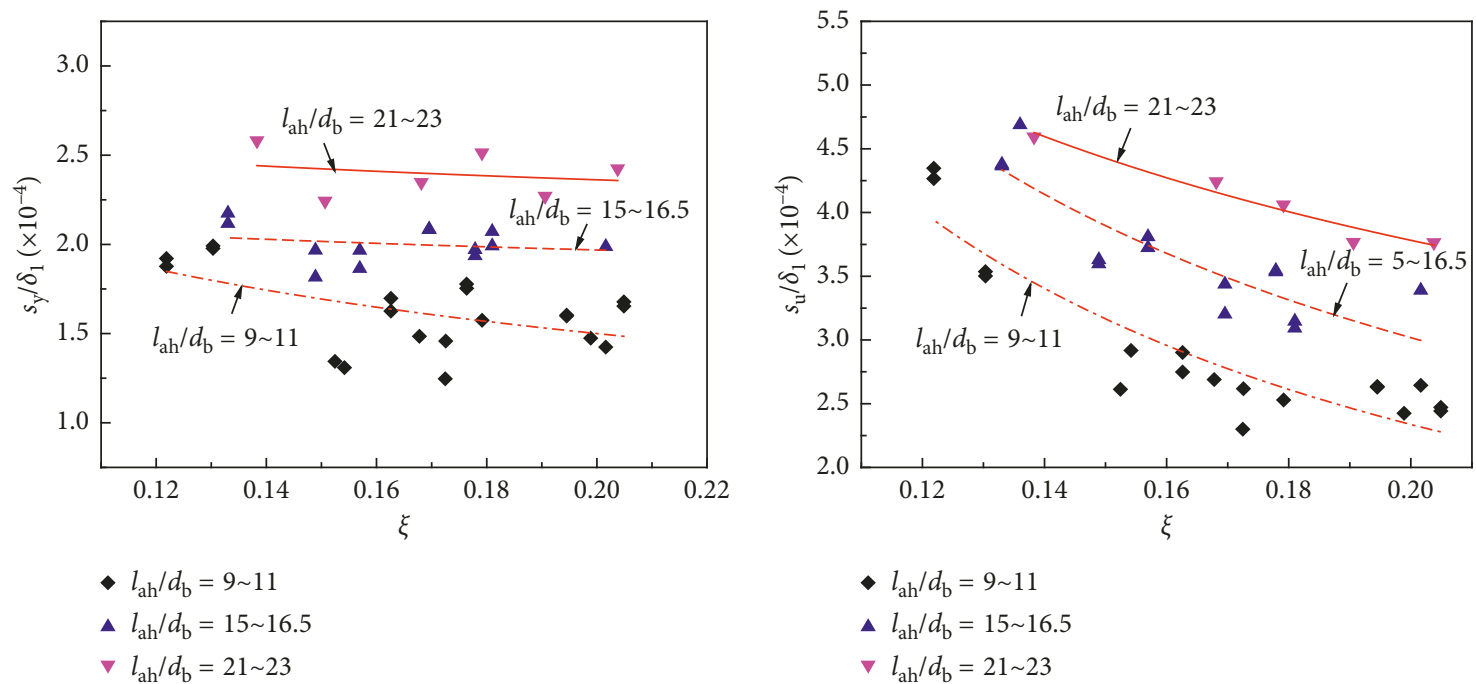

(a)

(b)

Figure 16: Effect of $\xi$ on (a) $s_{\mathrm{y}} / \delta_{1}$ and (b) $s_{\mathrm{u}} / \delta_{1}$. 
section $\varepsilon_{\mathrm{su}}$ is the maximum. Under the same bond condition, $\varepsilon_{\text {su }}$ can be regarded to be positively related to slippage. Meanwhile, based on the equilibrium equation for the cross section, $\varepsilon_{\text {su }}$ decreases with an increase in $\xi$. Thus, an increase in $\xi$ leads to a reduction in $s_{\mathrm{u}}$. The curve of the power function, shown in Figure 16(b), was fitted as the coefficient $\delta_{2}$ to consider the influence of $\xi$ on $s_{\mathrm{u}}$ as follows:

$$
\delta_{2}=\xi^{-0.68}
$$

By combining equations (12) and (13), we find that the increase in $\xi$ has a more significant influence on the decrease in $s_{\mathrm{u}}$ than the decrease in the depth of the tensile zone. As shown in Figure 17, $\theta_{\mathrm{u} \text {,slip }}$ decreases with the increase in $\xi$.

4.3. Effect of Yield Strength of Reinforcement. Figure 18 shows the variation in the slippage $s$ with respect to the yield strength $f_{\mathrm{y}}$ at the yielding and nominal ultimate states. The design parameters for each comparison group are the same except for $f_{\mathrm{y}}$, as shown in the legend. As $f_{\mathrm{y}}$ increases from $540 \mathrm{MPa}$ to $654 \mathrm{MPa}$, an increasing trend of $s_{\mathrm{y}}$ and $s_{\mathrm{u}} / \delta_{2}$ is observed. According to statistics, $s_{\mathrm{y}}$ and $s_{\mathrm{u}}$ increase by an average of $17.4 \%$ and $12.2 \%$, respectively. The increase in $f_{\mathrm{y}}$ accelerates the bond failure between the reinforcement and the concrete at the yielding and nominal ultimate states and in turn improves the ability of the strain penetration, thus leading to an increase in additional fixed-end rotation. A comparison between Figures 18(a) and 18(b) shows that the slopes of the trendlines in Figure 18(a) are greater than those in Figure 18(b). This implies that the growth rate of $s_{\mathrm{y}}$ is faster than that of $s_{\mathrm{u}}$ with the increase in $f_{\mathrm{y}}$. As a result, the influence of the strain penetration on the additional fixed-end rotation at the early stages before the yielding should be given special attention when high-strength steel bars are used as the tensile reinforcement in beam-column connections.

4.4. Effect of Concrete Tensile Strength. The following are the three components of the bond forces between reinforcement and concrete: adhesion on the reinforcement surface, friction due to concrete shrinkage, and mechanical interlocking between lugs and concrete. The increase in the tensile strength of the concrete $f_{\mathrm{t}}$ improves the adhesion and mechanical interlocking forces and delays the cracking of the tensile concrete around the reinforcement. Experimental studies have shown that the ultimate bond strength between deformed steel bars and concrete increases is in proportion with the concrete tensile strength $f_{\mathrm{t}}$ [27]. Consequently, an increase in $f_{\mathrm{t}}$ will result in a faster decline in the rebar strain along the embedment length and subsequently decrease the slippage at the beam-column interface. From the experimental results presented in this paper, the variations in slippage $s_{\mathrm{y}}$ and $s_{\mathrm{u}}$ with the concrete tensile strength $f_{\mathrm{t}}$ are shown in Figure 19, where a slightly decreased trend is observed. Because of the discrete characteristics and the relatively close grade of the

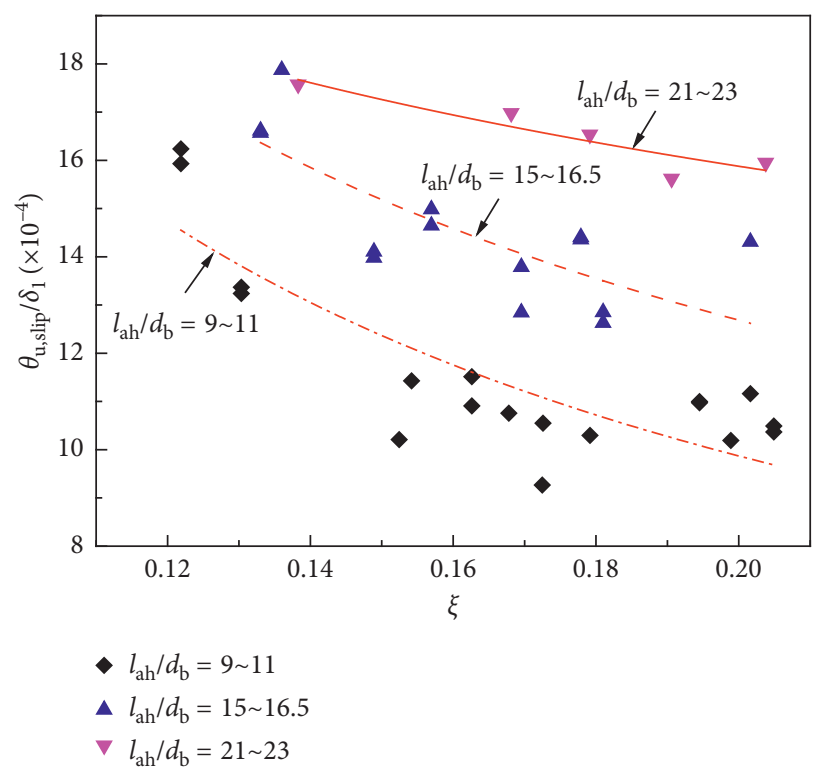

FIgURE 17: Effect of $\xi$ on $\theta_{\mathrm{u}, \mathrm{slip}} / \delta_{1}$.

concrete, a certain fluctuation existed in the results and the extent of decrease was not significant.

\subsection{Effect of Straight Embedment Length of Reinforcement.} The straight embedment length of the reinforcement in beam-column connection is another factor that is believed to effect the additional fixed-end rotation. A related study conducted by Sezen and Setzler [12] concluded that the steel bars with various embedment lengths would behave similarly in a certain length range and the minimum embedment length was later determined. As mentioned in Section 3.3, $12 d_{\mathrm{b}}$ is considered the lower limit of the embedment length in this paper. From the test results, the effect of the relative straight embedment length $l_{\mathrm{ah}} / d_{\mathrm{b}}$ on the slippage $s$ is obtained, as shown in Figure 20. When the values of the other parameters are fixed, $s_{\mathrm{y}}$ and $s_{\mathrm{u}}$ tend to increase as a power function as $l_{\mathrm{ah}} / d_{\mathrm{b}}$ varies from 8 to 24 . The reason for the same is given in Figure 20.

As shown in Figure 13, the rebar strain decreases from maximum at the beam-column interface to zero at the unloaded end along the development length $L_{\mathrm{d}}$. However, the embedded length in practical design is usually no greater than $L_{\mathrm{d}}$. In these cases, the unloaded end is stressed. Certain values of the strain at the end of the bars (the middle point of the continuous steel bars embedded in the interior beamcolumn connection sustained by the symmetrical load and the free-end point of the steel bars anchored in the exterior beam-column connection) are obtained, as shown in Figures 8 and 9. Although the reinforcement strain attenuates along the embedment length, the contribution of the rebar strain near the unloaded end to the slippage cannot be ignored. Based on equations (2) and (3), an increase in $l_{\mathrm{ah}} / d_{\mathrm{b}}$ enlarges the upper limit of the strain integration and consequently increases the slippage of reinforcement. However, when it exceeds the development length, the redundant embedment length is invalid. In summary, increasing $l_{\mathrm{ah}} / d_{\mathrm{b}}$ 

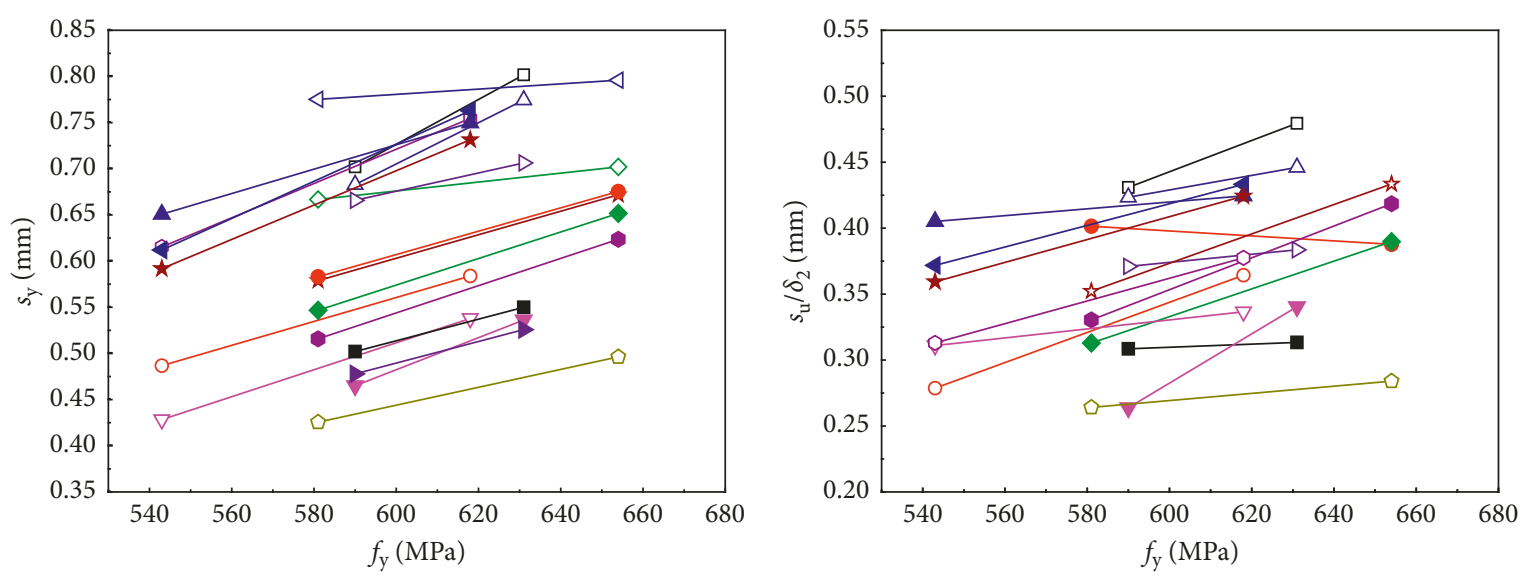

$$
\begin{aligned}
& -f_{\mathrm{ct}}=3.41 \mathrm{MPa}, l_{\mathrm{a}} / d_{\mathrm{b}}=11, d=18 \mathrm{~mm} \\
& \rightarrow f_{\mathrm{ct}}=3.72 \mathrm{MPa}, l_{\mathrm{a}} / d_{\mathrm{b}}=11, d=18 \mathrm{~mm} \\
& \rightarrow f_{\mathrm{ct}}=4.28 \mathrm{MPa}, l_{\mathrm{a}} / d_{\mathrm{b}}=11, d=18 \mathrm{~mm} \\
& \rightarrow-f_{\mathrm{ct}}=3.43 \mathrm{MPa}, l_{\mathrm{ah}} / d_{\mathrm{b}}=23, d=18 \mathrm{~mm} \\
& \rightarrow-f_{\mathrm{ct}}=3.66 \mathrm{MPa}, l_{\mathrm{ah}} / d_{\mathrm{b}}=9, d=22 \mathrm{~mm} \\
& \rightarrow f_{\mathrm{ct}}=4.10 \mathrm{MPa}, l_{\mathrm{ah}} / d_{\mathrm{b}}=21, d=18 \mathrm{~mm} \\
& \longrightarrow f_{\mathrm{ct}}=3.40 \mathrm{MPa}, l_{\mathrm{a}} / d_{\mathrm{b}}=15, d=20 \mathrm{~mm} \\
& \checkmark f_{\mathrm{ct}}=3.72 \mathrm{MPa}, l_{\mathrm{a}} / d_{\mathrm{b}}=15, d=20 \mathrm{~mm} \\
& \leftrightarrow f_{\mathrm{ct}}=4.21 \mathrm{MPa}, l_{\mathrm{a}} / d_{\mathrm{b}}=15, d=20 \mathrm{~mm} \\
& -\circ f_{\mathrm{ct}}=3.43 \mathrm{MPa}, l_{\mathrm{ah}} / d_{\mathrm{b}}=10, d=22 \mathrm{~mm} \\
& \checkmark f_{\mathrm{ct}}=3.64 \mathrm{MPa}, l_{\mathrm{ah}} / d_{\mathrm{b}}=16, d=20 \mathrm{~mm} \\
& -0-f_{\mathrm{ct}}=4.10 \mathrm{MPa}, l_{\mathrm{ah}} / d_{\mathrm{b}}=14, d=22 \mathrm{~mm} \\
& \neg-f_{\mathrm{ct}}=4.10 \mathrm{MPa}, l_{\mathrm{ah}} / d_{\mathrm{b}}=8.5, d=20 \mathrm{~mm} \\
& \neg f_{\mathrm{ct}}=3.61 \mathrm{MPa}, l_{\mathrm{a}} / d_{\mathrm{b}}=18, d=22 \mathrm{~mm} \\
& \longleftarrow f_{\mathrm{ct}}=3.72 \mathrm{MPa}, l_{\mathrm{a}} / d_{\mathrm{b}}=18, d=22 \mathrm{~mm} \\
& \star f_{\mathrm{ct}}=4.18 \mathrm{MPa}, l_{\mathrm{a}} / d_{\mathrm{b}}=18, d=22 \mathrm{~mm} \\
& \triangle f_{\mathrm{ct}}=3.66 \mathrm{MPa}, l_{\mathrm{ah}} / d_{\mathrm{b}}=22, d=18 \mathrm{~mm} \\
& \triangleleft f_{\mathrm{ct}}=3.64 \mathrm{MPa}, l_{\mathrm{ah}} / d_{\mathrm{b}}=21, d=20 \mathrm{~mm} \\
& \text { \# } f_{\mathrm{ct}}=4.10 \mathrm{MPa}, l_{\mathrm{ah}} / d_{\mathrm{b}}=14, d=20 \mathrm{~mm}
\end{aligned}
$$

(a)

$$
\begin{aligned}
& \text { - } f_{\mathrm{ct}}=3.41 \mathrm{MPa}, l_{\mathrm{a}} / d_{\mathrm{b}}=11, d=18 \mathrm{~mm} \\
& \nabla f_{\mathrm{ct}}=3.72 \mathrm{MPa}, l_{\mathrm{a}} / d_{\mathrm{b}}=11, d=18 \mathrm{~mm} \\
& \rightarrow f_{\mathrm{ct}}=4.28 \mathrm{MPa}, l_{\mathrm{a}} / d_{\mathrm{b}}=11, d=18 \mathrm{~mm} \\
& \rightarrow-f_{\mathrm{ct}}=3.43 \mathrm{MPa}, l_{\mathrm{ah}} / d_{\mathrm{b}}=23, d=18 \mathrm{~mm} \\
& \rightarrow-f_{\mathrm{ct}}=3.66 \mathrm{MPa}, l_{\mathrm{ah}} / d_{\mathrm{b}}=9, d=22 \mathrm{~mm} \\
& \rightarrow f_{\mathrm{ct}}=4.10 \mathrm{MPa}, l_{\mathrm{ah}} / d_{\mathrm{b}}=21, d=18 \mathrm{~mm} \\
& \longrightarrow f_{\mathrm{ct}}=3.40 \mathrm{MPa}, l_{\mathrm{a}} / d_{\mathrm{b}}=15, d=20 \mathrm{~mm} \\
& \checkmark f_{\mathrm{ct}}=3.72 \mathrm{MPa}, l_{\mathrm{a}} / d_{\mathrm{b}}=15, d=20 \mathrm{~mm} \\
& \rightarrow f_{\mathrm{ct}}=4.21 \mathrm{MPa}, l_{\mathrm{a}} / d_{\mathrm{b}}=15, d=20 \mathrm{~mm} \\
& -0-f_{\mathrm{ct}}=3.43 \mathrm{MPa}, l_{\mathrm{ah}} / d_{\mathrm{b}}=10, d=22 \mathrm{~mm} \\
& \checkmark f_{\mathrm{ct}}=3.64 \mathrm{MPa}, l_{\mathrm{ah}} / d_{\mathrm{b}}=16, d=20 \mathrm{~mm} \\
& -0-f_{\mathrm{ct}}=4.10 \mathrm{MPa}, l_{\mathrm{ah}} / d_{\mathrm{b}}=14, d=22 \mathrm{~mm} \\
& \neg-f_{\mathrm{ct}}=4.10 \mathrm{MPa}, l_{\mathrm{ah}} / d_{\mathrm{b}}=8.5, d=20 \mathrm{~mm} \\
& \leftarrow f_{\mathrm{ct}}=3.61 \mathrm{MPa}, l_{\mathrm{a}} / d_{\mathrm{b}}=18, d=22 \mathrm{~mm} \\
& \dashv f_{\mathrm{ct}}=3.72 \mathrm{MPa}, l_{\mathrm{a}} / d_{\mathrm{b}}=18, d=22 \mathrm{~mm} \\
& \star f_{\mathrm{ct}}=4.18 \mathrm{MPa}, l_{\mathrm{a}} / d_{\mathrm{b}}=18, d=22 \mathrm{~mm} \\
& \triangle f_{\mathrm{ct}}=3.66 \mathrm{MPa}, l_{\mathrm{ah}} / d_{\mathrm{b}}=22, d=18 \mathrm{~mm} \\
& \triangleleft f_{\mathrm{ct}}=3.64 \mathrm{MPa}, l_{\mathrm{ah}} / d_{\mathrm{b}}=21, d=20 \mathrm{~mm} \\
& \text { 的 } f_{\mathrm{ct}}=4.10 \mathrm{MPa}, l_{\mathrm{ah}} / d_{\mathrm{b}}=14, d=20 \mathrm{~mm}
\end{aligned}
$$

(b)

FigURE 18: Effect of $f_{\mathrm{y}}$ on (a) $s_{\mathrm{y}}$ and (b) $s_{\mathrm{u}} / \delta_{2}$.

within a certain range is beneficial to the additional fixedend rotation.

\section{Proposed Model of Additional Fixed- Rotation at Yielding and Nominal Ultimate States}

Based on the development trend of the parameters analysed in the parametric study above, a three-dimensional coordinate system is established with $d_{\mathrm{b}}\left(f_{\mathrm{y}} / f_{t}\right), l_{\mathrm{ah}} / d_{\mathrm{b}}$ as the horizontal axis, and $s$ as the vertical axis. The test data points are incorporated in the coordinate system, as shown in Figure 21. The fitting surfaces in terms of the slippage $s$ at the yielding and nominal ultimate states are obtained from the multivariable regression analysis considering all the main parameters. The expressions of the fitting surfaces are as follows, wherein $12 d_{\mathrm{b}} \leq l_{\mathrm{ah}} \leq 24 d_{\mathrm{b}}$ is based on the experimental results:

$$
\begin{aligned}
& s_{\mathrm{y}}=4.770 \times 10^{-5}\left(\frac{d_{\mathrm{b}} f_{\mathrm{y}}}{f_{\mathrm{ct}}}\right)\left(\frac{l_{\mathrm{ah}}}{d_{b}}\right)^{0.5117}, \\
& s_{\mathrm{u}}=\frac{3.191 \times 10^{-5}}{\xi^{0.68}}\left(\frac{d_{\mathrm{b}} f_{\mathrm{y}}}{f_{\mathrm{ct}}}\right)\left(\frac{l_{\mathrm{ah}}}{d_{\mathrm{b}}}\right)^{0.4195} .
\end{aligned}
$$

Then, the additional fixed-rotations $\theta_{\mathrm{y}, \text { slip }}$ and $\theta_{\mathrm{u}, \mathrm{slip}}$ can be determined with equations (11)-(15):

$$
\begin{aligned}
& \theta_{\mathrm{y}, \text { slip }}=\frac{s_{\mathrm{y}}}{d-x_{\mathrm{c}, \mathrm{y}}}=\frac{4.770 \times 10^{-5}\left(d_{\mathrm{b}} f_{\mathrm{y}} / f_{\mathrm{ct}}\right)\left(l_{\mathrm{ah}} / d_{\mathrm{b}}\right)^{0.5117}}{0.8 d(1-0.95 \xi)}, \\
& \theta_{\mathrm{u}, \mathrm{slip}}=\frac{s_{\mathrm{u}}}{d-x_{\mathrm{c}, \mathrm{u}}}=\frac{3.191 \times 10^{-5}\left(d_{\mathrm{b}} f_{\mathrm{y}} / f_{\mathrm{ct}}\right)\left(l_{\mathrm{ah}} / d_{\mathrm{b}}\right)^{0.4195}}{\xi^{0.68} d(1-1.25 \xi)} .
\end{aligned}
$$




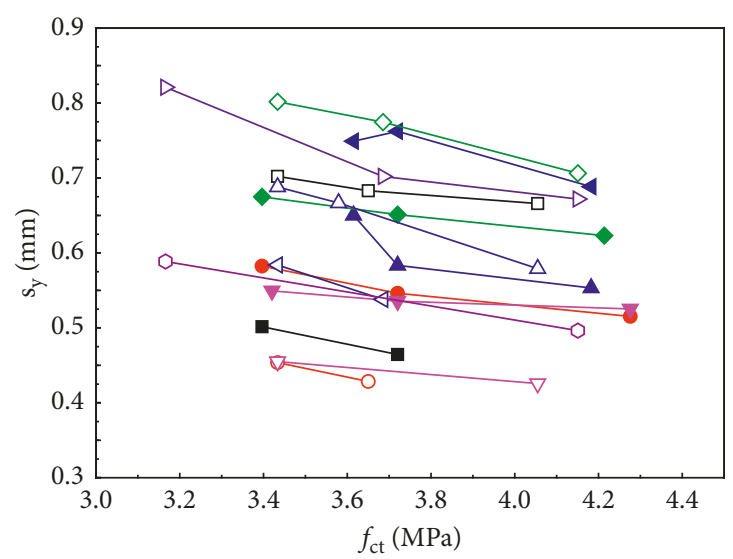

$\rightarrow-f_{\mathrm{y}}=590 \mathrm{MPa}, l_{\mathrm{ah}} / d=11, d=18 \mathrm{~mm}$

$\rightarrow f_{\mathrm{y}}=613 \mathrm{MPa}, l_{\mathrm{ah}} / d=11, d=18 \mathrm{~mm}$

$\neg \square f_{\mathrm{y}}=590 \mathrm{MPa}, l_{\mathrm{ah}} / d=22, d=18 \mathrm{~mm}$

$\rightarrow-f_{\mathrm{y}}=581 \mathrm{MPa}, l_{\mathrm{ah}} / d=8.5, d=20 \mathrm{~mm}$

$\rightarrow f_{\mathrm{y}}=654 \mathrm{MPa}, l_{\mathrm{ah}} / d=18, d=20 \mathrm{~mm}$

$\longrightarrow f_{\mathrm{y}}=581 \mathrm{MPa}, l_{\mathrm{ah}} / d=15, d=20 \mathrm{~mm}$

$\checkmark f_{\mathrm{y}}=654 \mathrm{MPa}, l_{\mathrm{ah}} / d=15, d=20 \mathrm{~mm}$

$-\circ f_{\mathrm{y}}=543 \mathrm{MPa}, l_{\mathrm{ah}} / d=9, d=22 \mathrm{~mm}$

$\checkmark f_{\mathrm{y}}=613 \mathrm{MPa}, l_{\mathrm{ah}} / d=23, d=18 \mathrm{~mm}$

- $-f_{\mathrm{y}}=654 \mathrm{MPa}, l_{\mathrm{ah}} / d=10, d=20 \mathrm{~mm}$

$\leftarrow f_{\mathrm{y}}=543 \mathrm{MPa}, l_{\mathrm{ah}} / d=18, d=22 \mathrm{~mm}$

4 $f_{\mathrm{y}}=618 \mathrm{MPa}, l_{\mathrm{ah}} / d=18, d=22 \mathrm{~mm}$

$\triangle f_{\mathrm{y}}=581 \mathrm{MPa}, l_{\mathrm{ah}} / d=14, d=20 \mathrm{~mm}$

$\triangleleft-f_{\mathrm{y}}=618 \mathrm{MPa}, l_{\mathrm{ah}} / d=10, d=22 \mathrm{~mm}$

(a)

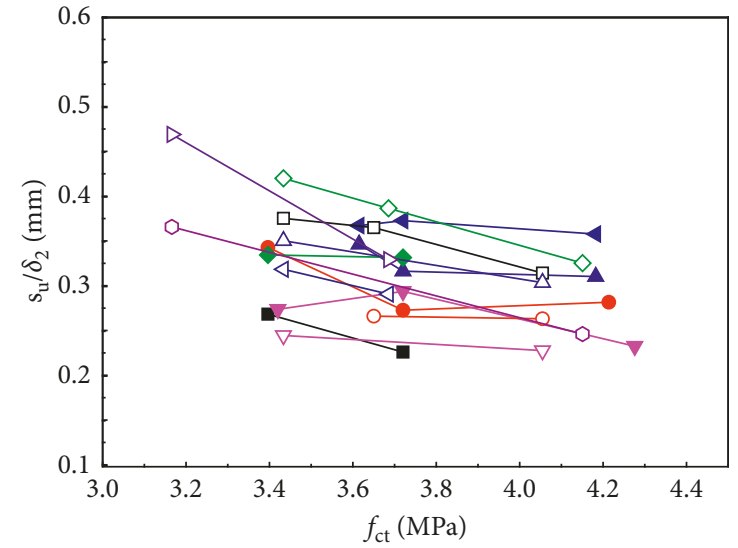

$f_{\mathrm{y}}=590 \mathrm{MPa}, l_{\mathrm{ah}} / d=11, d=18 \mathrm{~mm}$

$\rightarrow f_{\mathrm{y}}=613 \mathrm{MPa}, l_{\mathrm{ah}} / d=11, d=18 \mathrm{~mm}$

$\rightarrow-f_{\mathrm{y}}=590 \mathrm{MPa}, l_{\mathrm{ah}} / d=22, d=18 \mathrm{~mm}$

$\rightarrow-f_{\mathrm{y}}=581 \mathrm{MPa}, l_{\mathrm{ah}} / d=8.5, d=20 \mathrm{~mm}$

$\rightarrow f_{\mathrm{y}}=654 \mathrm{MPa}, l_{\mathrm{ah}} / d=18, d=20 \mathrm{~mm}$

$\longrightarrow f_{\mathrm{y}}=581 \mathrm{MPa}, l_{\mathrm{ah}} / d=15, d=20 \mathrm{~mm}$

$\checkmark f_{\mathrm{y}}=654 \mathrm{MPa}, l_{\mathrm{ah}} / d=15, d=20 \mathrm{~mm}$

$-0-f_{\mathrm{y}}=543 \mathrm{MPa}, l_{\mathrm{ah}} / d=9, d=22 \mathrm{~mm}$

$\checkmark f_{\mathrm{y}}=613 \mathrm{MPa}, l_{\mathrm{ah}} / d=23, d=18 \mathrm{~mm}$

- $-f_{\mathrm{y}}=654 \mathrm{MPa}, l_{\mathrm{ah}} / d=10, d=20 \mathrm{~mm}$

$\leftarrow f_{\mathrm{y}}=543 \mathrm{MPa}, l_{\mathrm{ah}} / d=18, d=22 \mathrm{~mm}$

$\longleftarrow f_{\mathrm{y}}=618 \mathrm{MPa}, l_{\mathrm{ah}} / d=18, d=22 \mathrm{~mm}$

$\neg-f_{\mathrm{y}}=581 \mathrm{MPa}, l_{\mathrm{ah}} / d=14, d=20 \mathrm{~mm}$

$\triangleleft f_{\mathrm{y}}=618 \mathrm{MPa}, l_{\mathrm{ah}} / d=10, d=22 \mathrm{~mm}$

(b)

Figure 19: Effect of $f_{\mathrm{ct}}$ on (a) $s_{\mathrm{y}}$ and (b) $s_{\mathrm{u}} / \delta_{2}$.

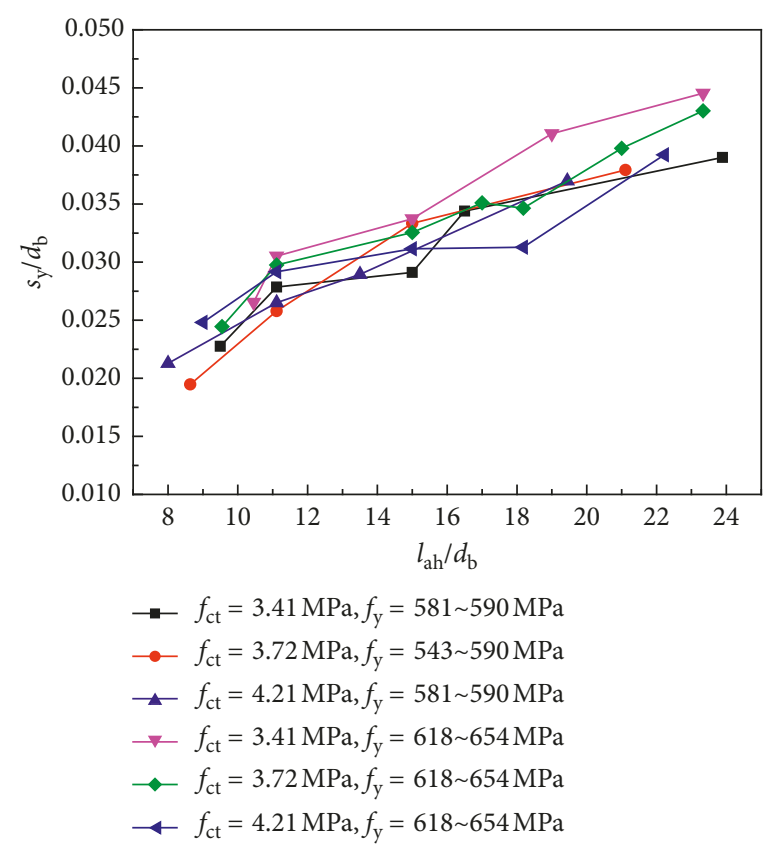

(a)

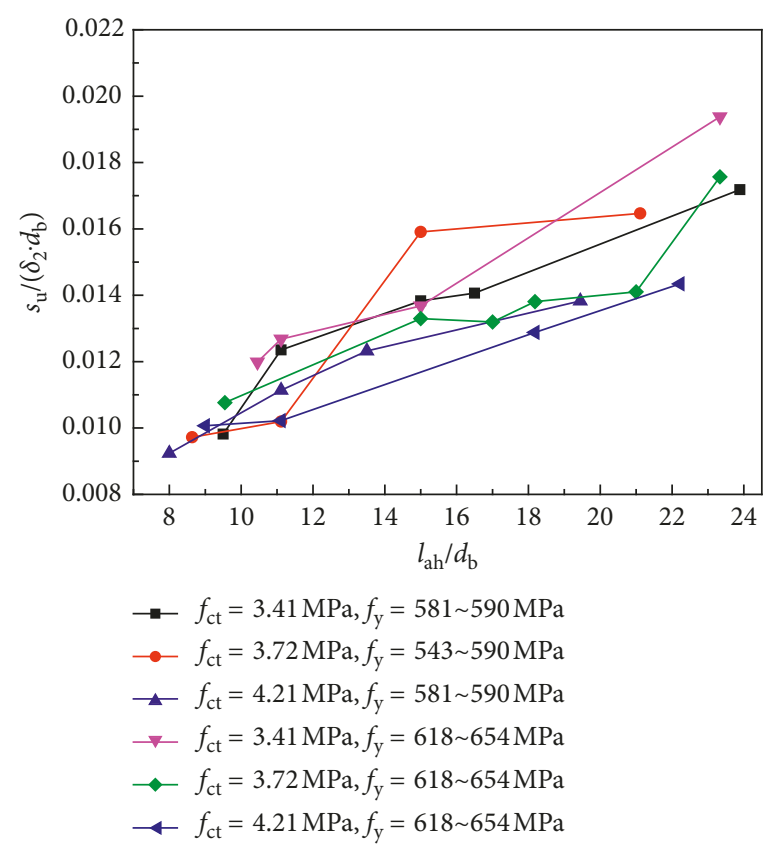

(b)

Figure 20: Effect of $l_{\mathrm{ah}} / d_{\mathrm{b}}$ on (a) $s_{\mathrm{y}}$ and (b) $s_{\mathrm{u}} / \delta_{2}$. 


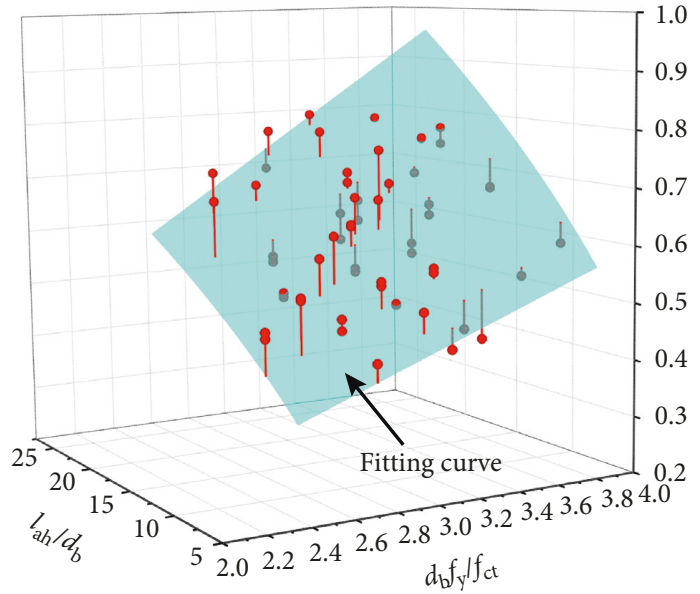

- Test data

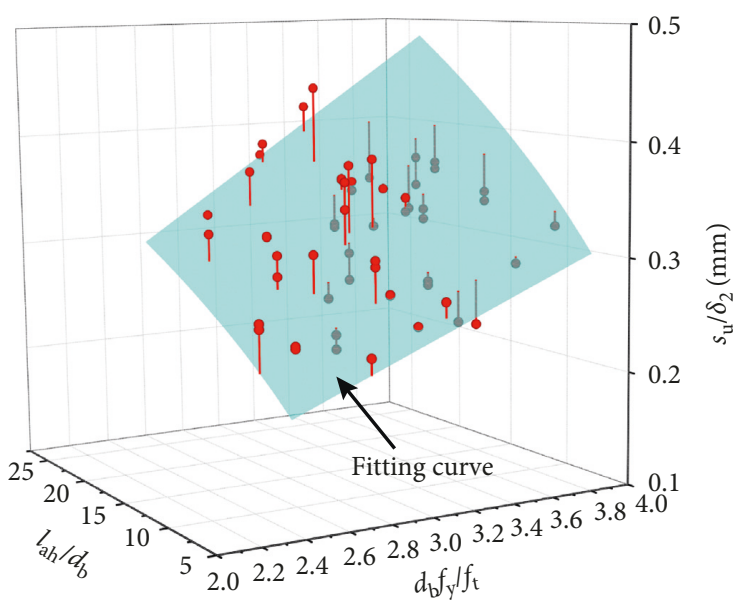

- Test data

(a)

(b)

Figure 21: Fitting curves of (a) $s_{\mathrm{y}}$ and (b) $s_{\mathrm{u}}$.

TABLE 10: Results of slippage $s_{\mathrm{y}}$ in the literatures.

\begin{tabular}{|c|c|c|c|c|c|c|}
\hline No. & $f_{\mathrm{y}}(\mathrm{MPa})$ & $f_{\mathrm{ct}}(\mathrm{MPa})$ & $d_{\mathrm{b}}(\mathrm{mm})$ & $l_{\mathrm{ah}}(\mathrm{mm})$ & $s_{\mathrm{y}}(\mathrm{mm})$ & Reference \\
\hline 1 & 350.3 & 2.29 & 19.1 & 762 & 0.5 & \multirow{3}{*}{ Shima et al. [28] } \\
\hline 2 & 610.2 & 2.29 & 19.1 & 762 & 0.9 & \\
\hline 3 & 819.8 & 2.29 & 19.1 & 762 & 1.6 & \\
\hline 4 & 708.8 & 2.69 & 12.7 & 355.6 & 0.8 & \multirow{2}{*}{ Mathey and Wastein [29] } \\
\hline 5 & 537.8 & 2.77 & 25.4 & 711.2 & 1.0 & \\
\hline 6 & 414.3 & 2.31 & 32.3 & 610 & 1.2 & \multirow{5}{*}{ Ueda et al. [3] } \\
\hline 7 & 331.6 & 2.20 & 32.3 & 610 & 0.9 & \\
\hline 8 & 414.3 & 2.36 & 32.3 & 375 & 1.1 & \\
\hline 9 & 468.8 & 2.48 & 25.4 & 457 & 0.9 & \\
\hline 10 & 438.5 & 2.84 & 19.1 & 610 & 0.6 & \\
\hline
\end{tabular}

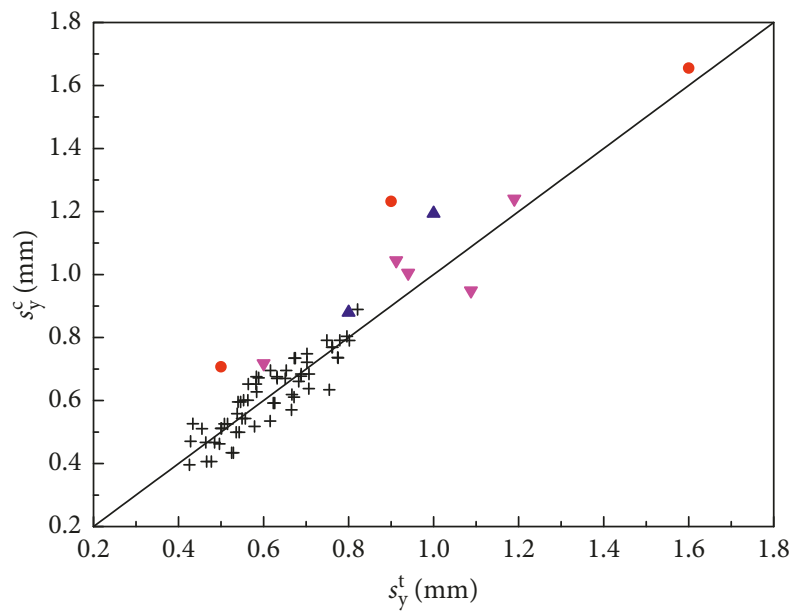

+ Test data in present paper $\Delta$ Mathey and wastein[29]

- Shima et al.[28]

$\checkmark$ Ueda et al.[3]

(a)

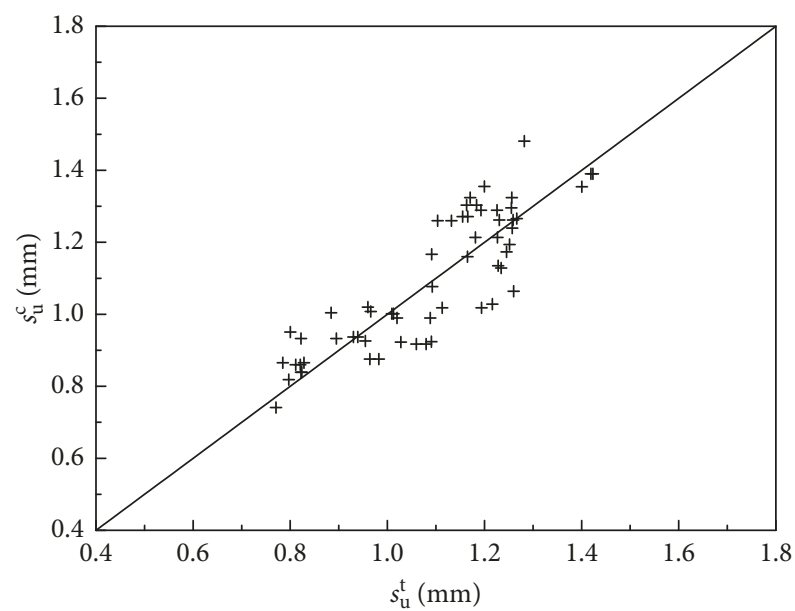

+ Test data in present paper

(b)

FIGURE 22: Comparison between calculation and experiment results of (a) $s_{\mathrm{y}}$ and (b) $s_{\mathrm{u}}$.

The parameters considered in the proposed models are widely used in engineering design, thus making the expression more simple and practical. To investigate the applicability of the proposed model, the test results of the ten specimens $[3,28,29]$ are provided for comparison. The properties of these specimens are summarized in Table 10. 
As most of the tests were pullout tests and were terminated soon after the reinforcement yielded at the loaded end, only the slippage of the reinforcement at the yielding state was compared. Figure 22 compares the predictions of $s_{\mathrm{y}}$ and $s_{\mathrm{u}}$ with the experimental results. The proposed model exhibits reasonable accuracy.

\section{Conclusion}

An accurate and simple determination of the additional fixed-end rotation at the beam-column interface due to the strain penetration can provide evidence for investigating the rotation of the plastic hinges. A series of reinforced concrete beam-column connections with variable design parameters were constructed and tested by applying a monotonic load at the beam end. A parametric study was carried out to study the effects of the yield strength of the reinforcement $f_{\mathrm{y}}$, tensile strength of the concrete $f_{\mathrm{ct}}$, diameter $d_{\mathrm{b}}$, and embedment length $l_{\mathrm{ah}}$ of the reinforcement in the beam-column connection on the additional fixed-end rotation. From the experiment results, the following conclusions can be drawn:

(1) The rebar strain distribution along the embedment length in the beam-column connection demonstrated the occurrence of strain penetration in the beam-column connection. A clear strain concentration could be observed near the beam-column interface at the nominal ultimate state. For different specimens with variable parameters under monotonic loading, the additional fixed-end rotation at the ultimate state was approximately 1.26-1.89 times greater than that at the yielding state.

(2) The additional fixed-end rotation increased with the increase in $f_{\mathrm{y}}$ and with the decrease in $f_{\mathrm{ct}}$. As $f_{\mathrm{y}}$ increased from $540 \mathrm{MPa}$ to $654 \mathrm{MPa}, s_{\mathrm{y}}$ and $s_{\mathrm{u}}$ increased by averages of $17.4 \%$ and $12.2 \%$, respectively. It indicated that when high-strength steel bars were used as the tensile reinforcement in beam-column connections, the effect of strain penetration on fixedend rotation was more obvious before the yielding state.

(3) As $l_{\mathrm{ah}} / d_{\mathrm{b}}$ varied from 12 to $24, s_{\mathrm{y}}$ and $s_{\mathrm{u}}$ tended to increase as a power function. Increasing $l_{\mathrm{ah}} / d_{\mathrm{b}}$ within a certain range was found to be beneficial to the additional fixed-end rotation.

(4) The depth of the neutral axis had almost no effect on $s_{\mathrm{y}}$; however, a power function reduction tendency of $s_{\mathrm{u}}$ was observed with the increase in the depth of the neutral axis. Along with the variation in the tensile zone depth, it was found from overall consideration that the increase in the depth of the neutral axis led to an increase in $\theta_{\mathrm{y} \text {,slip }}$ but slightly decreased $\theta_{\mathrm{u} \text {,slip. }}$

(5) A simple calculation model of the additional fixedend rotation was proposed for interior and exterior beam-column connections under monotonic loading at the yielding and nominal ultimate states. Parameters widely used in engineering design were considered in the model. The comparison between the prediction and experimental results showed good agreement.

\section{Data Availability}

The data used to support the findings of this study are available from the corresponding author upon request.

\section{Conflicts of Interest}

The authors declare that they have no conflicts of interest.

\section{Acknowledgments}

Support for this research from the National Natural Science Foundation of China (NSFC, Grant no. 51378146) is gratefully acknowledged.

\section{References}

[1] X.-M. Zhao, Y.-F. Wu, and A. Y. T. Leung, “Analyses of plastic hinge regions in reinforced concrete beams under monotonic loading," Engineering Structures, vol. 34, no. 1, pp. 466-482, 2012.

[2] K. G. Megalooikonomou, S. P. Tastani, and S. J. Pantazopoulou, "Effect of yield penetration on column plastic hinge length," Engineering Structures, vol. 156, pp. 161-174, 2018.

[3] T. Ueda, I. Lin, and N. M. Hawkins, "Beam bar anchorages in exterior column-beam connections," ACI Structural Journal, vol. 83, no. 3, pp. 412-422, 1986.

[4] P. E. Mergos and A. J. Kappos, "Estimating fixed-end rotations of reinforced concrete members at yielding and ultimate," Structural Concrete, vol. 16, no. 4, pp. 537-545, 2016.

[5] N. M. Hawkins, I. Lin, and T. Ueda, "Anchorage of reinforcing bars for seismic forces," ACI Structural Journal, vol. 84, no. 5, pp. 407-418, 1987.

[6] G. M. S. Alva and A. L. H. d. C. El Debs, "Moment-rotation relationship of RC beam-column connections: experimental tests and analytical model," Engineering Structures, vol. 56, no. 6, pp. 1427-1438, 2013.

[7] G. Russo, G. Zingone, and F. Romano, "Analytical solution for bond-slip of reinforcing bars in R.C. Joints," Journal of Structural Engineering, vol. 116, no. 2, pp. 336-355, 1990.

[8] S. Hong and S. K. Park, "Uniaxial bond stress-slip relationship of reinforcing bars in concrete," Advances in Materials Science and Engineering, vol. 2012, Article ID 328570, 12 pages, 2012.

[9] P. E. Mergos, "The anchorage-slip effect on direct displacementbased design of R/C bridge piers for limiting material strains," Computers and Concrete, vol. 11, no. 6, pp. 493-513, 2013.

[10] J. M. Alsiwat and M. Saatcioglu, "Reinforcement anchorage slip under monotonic loading," Journal of Structural Engineering, vol. 118, no. 9, pp. 2421-2438, 1992.

[11] H. Sezen and J. P. Moehle, "Seismic tests of concrete columns with light transverse reinforcement," ACI Structural Journal, vol. 103, no. 6, pp. 842-849, 2006.

[12] H. Sezen and E. J. Setzler, "Reinforcement slip in reinforced concrete columns," ACI Structural Journal, vol. 105, no. 3, pp. 280-289, 2008.

[13] S. P. Tastani and S. J. Pantazopoulou, "Yield penetration in seismically loaded anchorages: effects on member deformation capacity," Earthquakes and Structures, vol. 5, no. 5, pp. 527-552, 2013. 
[14] Z. Pan, S. Guner, and F. J. Vecchio, "Modeling of interior beam-column joints for nonlinear analysis of reinforced concrete frames," Engineering Structures, vol. 142, pp. 182191, 2016.

[15] M. Saatcioglu and G. Ozcebe, "Response of reinforced concrete columns to simulated seismic loading," ACI Structural Journal, vol. 86, no. 1, pp. 3-12, 1989.

[16] L. N. Lowes and A. Altoontash, "Modeling reinforcedconcrete beam-column joints subjected to cyclic loading," Journal of Structural Engineering, vol. 129, no. 12, pp. 16861697, 2003.

[17] C.-L. Ning, B. Yu, and B. Li, "Beam-column joint model for nonlinear analysis of non-seismically detailed reinforced concrete frame," Journal of Earthquake Engineering, vol. 20, no. 3, pp. 476-502, 2016.

[18] J. Zhao and S. Sritharan, "Modeling of strain penetration effects in fiber-based analysis of reinforced concrete structures," ACI Structural Journal, vol. 104, no. 2, pp. 133-141, 2007.

[19] T. Paulay and M. J. N. Priestley, Seismic Design of Reinforced Concrete and Masonry Buildings, John Wiley \& Sons, New York, NY, USA, 1992.

[20] Code of China, Code for Design of Concrete Structures GB 50010-2010, China Architecture and Building Press, Beijing, China, 2011, in Chinese.

[21] ACI 318-14, Building Code Requirements for Structural Concrete and Commentary, American Concrete Institute, Farmington Hills, MI, U.S.A, 2012.

[22] P. Soroushian, K. Obaseki, M. Nagi, and M. Rojas, "Pullout behavior of hooked bars in exterior beam-column connections," ACI Structural Journal, vol. 85, no. 3, pp. 269-276, 1988.

[23] European Committee for Standardization, Eurocode 2: Design of Concrete Structures-Part 1-1: General Rules and Rules for Buildings, European Committee for Standardization, Brussels, Belgium, 2004.

[24] M. J. N. Priestley and R. Park, "Strength and ductility of concrete bridge columns under seismic loading," ACI Structural Journal, vol. 84, no. 1, pp. 61-76, 1987.

[25] T. B. Panagiotakos and M. N. Fardis, "Deformations of reinforced concrete members at yielding and ultimate," ACI Structural Journal, vol. 98, no. 2, pp. 135-148, 2001.

[26] European Committee for Standardization, Eurocode 8: Design provisions of Structures for Earthquake Resistance-Part 3: Assessment and Retrofitting of Buildings, European Committee for Standardization, Brussels, Belgium, 2005.

[27] A. Losberg and P. A. Olsson, "Bond failure of deformed reinforcing bars based on the longitudinal splitting effect of the bars," ACI Structural Journal, vol. 76, no. 1, pp. 5-18, 1979.

[28] H. Shima, L. Chou, and H. Okamura, "Bond characteristic in post yield range of deformed bars," Concrete Library of JSCE, vol. 10, pp. 113-124, 1987.

[29] R. G. Mathey and D. Watstein, "Investigation of bond in beam and pull-out specimens with high-yield-strength deformed bars," ACI Structural Journal, vol. 57, no. 3, pp. 1071-1090, 1961. 


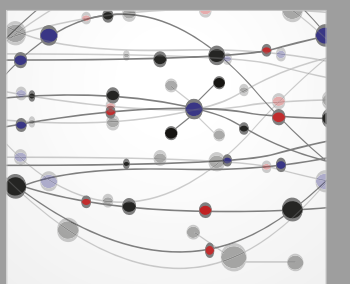

The Scientific World Journal
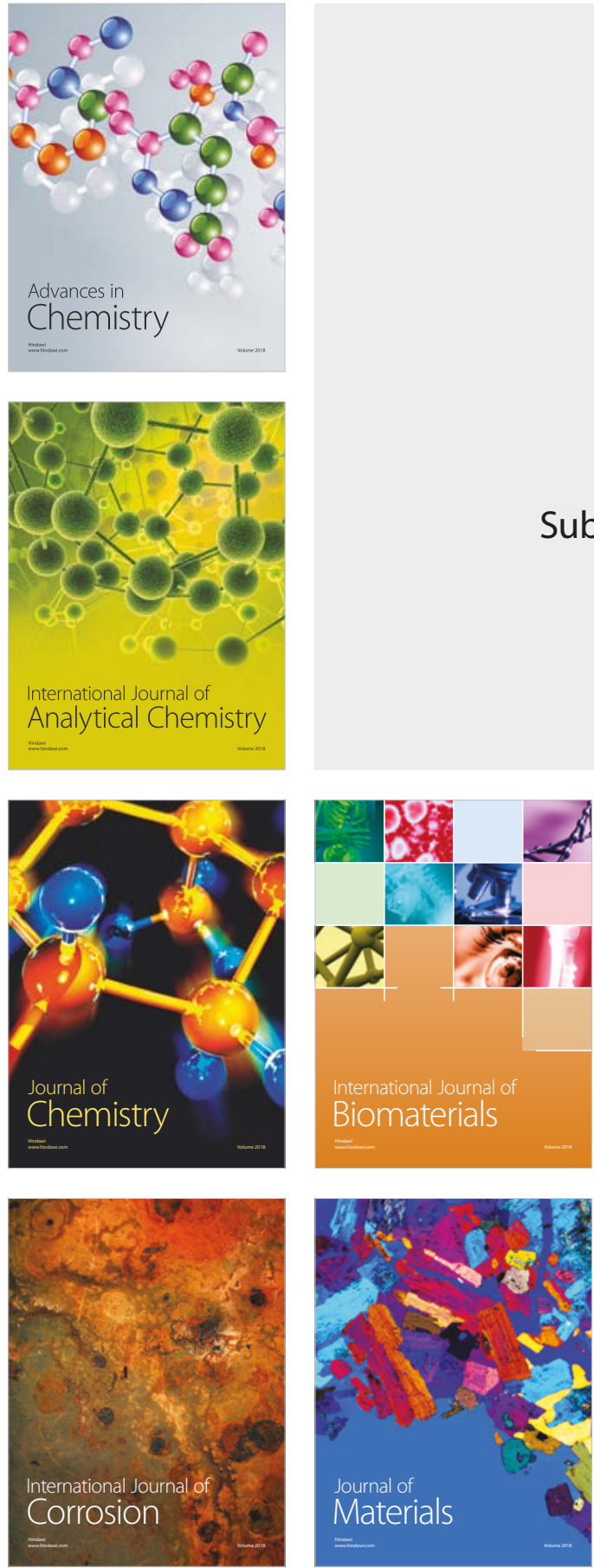

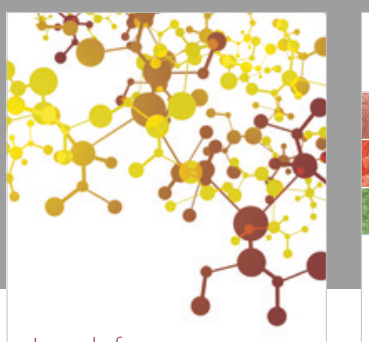

Journal of

Applied Chemistry
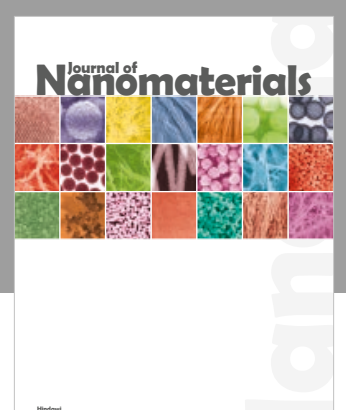

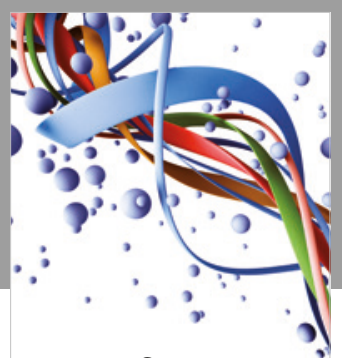

Scientifica

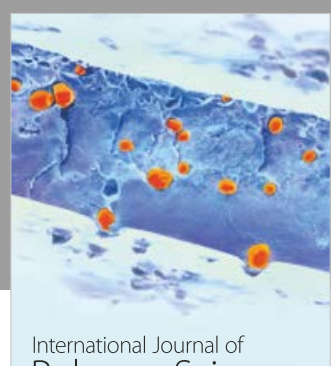

Polymer Science

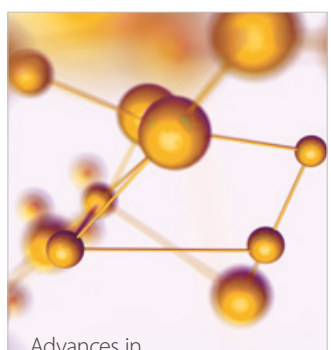

Physical Chemistry
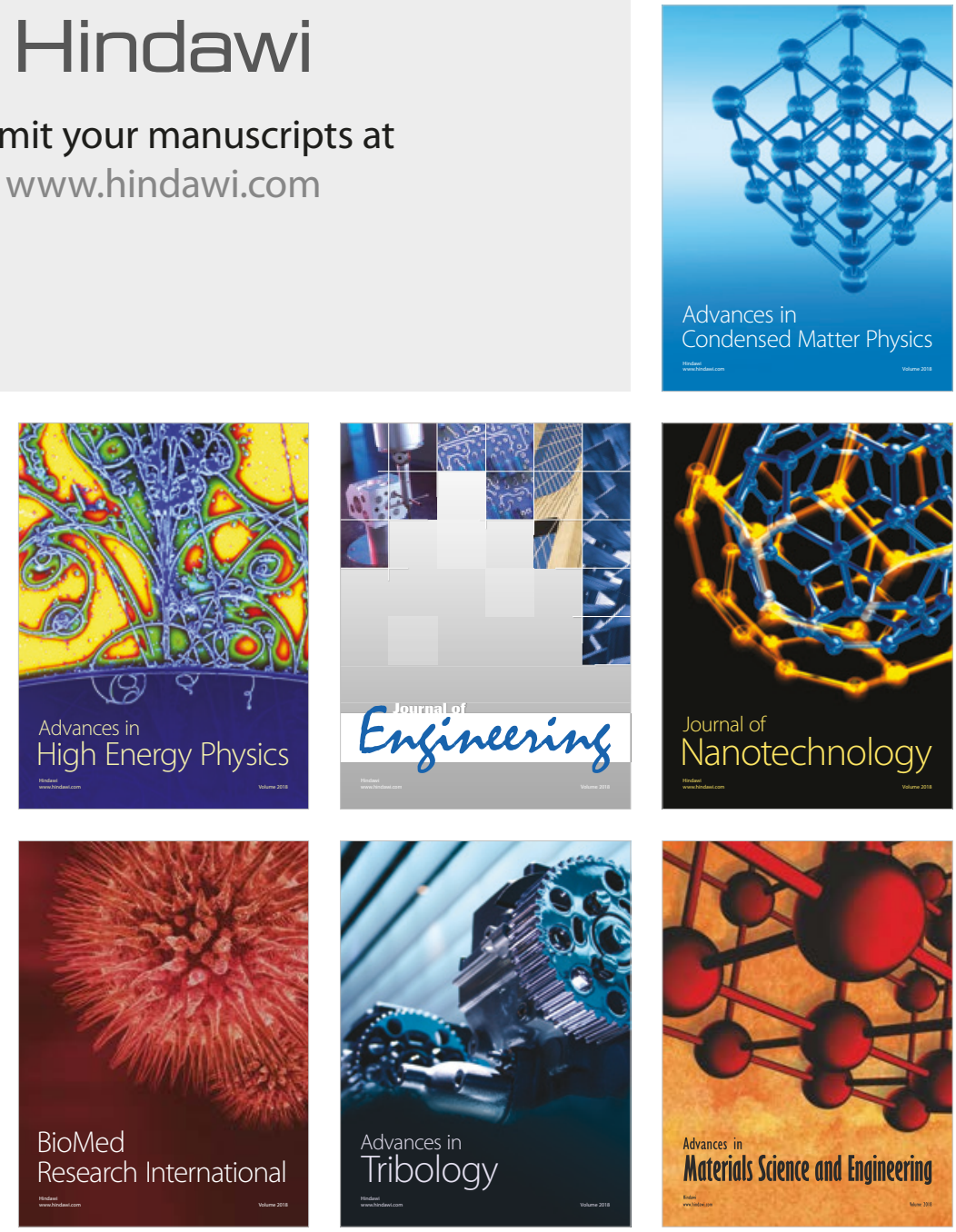